\title{
Characteristics of Observed Peak Amplitude for Strong Ground Motion from the 1995 Hyogoken Nanbu (Kobe) Earthquake
}

\author{
by Yoshimitsu Fukushima, Kojiro Irikura, Tomiichi Uetake, and Hisashi Matsumoto
}

\begin{abstract}
Over 200 peak amplitudes of strong motion were observed at distances of less than $250 \mathrm{~km}$ from the fault during the 1995 Hyogo-ken Nanbu (Kobe) earthquake. We analyzed the attenuation of the peak-ground acceleration and velocity as a function of distance and geological site conditions. The observed peak amplitudes agree well with those predicted by an empirical attenuation relation that was developed for Japanese earthquakes. This demonstrates that on average the peak amplitude of the ground motion generated by this damaging earthquake did not exceed the level predicted by the empirical attenuation relation. We found a significant effect of the surface geology on the observed ground-motion peak amplitude. In particular for soft-soil sites, located near the fault, the peak-horizontal acceleration decreases rapidly with distance as a result of the nonlinear response of soils. In order to take into account the effect of the site conditions we introduced correction factors to the existing attenuation relation. This resulted in a significant reduction of the residuals between the predicted and observed peak amplitudes. Based on the attenuation relation corrected for the site condition effect we generated a map of horizontal peakground acceleration in the Kobe and Osaka area for the Kobe earthquake. The area of simulated large ground motion agrees well with the severe damage zone of intensity VII, JMA scale.
\end{abstract}

\section{Introduction}

More than 6,500 people were killed and 170,000 buildings were destroyed in the Hanshin and Awaji areas as a result of the 17 January 1995 Hyogo-ken Nanbu earthquake. The origin time and hypocenter of the event given by the Japan Meteorological Agency (JMA) were 05h46m52sec (local time) and longitude $135^{\circ} 2.6^{\prime} \mathrm{E}$, latitude $34^{\circ} 36.4^{\prime} \mathrm{N}$, respectively, and the focal depth was $14.3 \mathrm{~km}$. The magnitude was $M_{\mathrm{j}} 7.2$ determined by the JMA, $M_{\mathrm{s}} 6.8$ by the U.S. Geological Survey, and $M_{\mathrm{w}} 6.9$ by Harvard University and Kikuchi (1995) from a seismic moment of $2.5 \times 10^{26}$ dyne $\mathrm{cm}$. The JMA intensity was VII throughout a narrow beltlike area stretching from Awaji Island to Nishinomiya City east of Kobe. The surface fault trace in the southwest part of the source area was in evidence along the Nojima fault in the Hokutan-cho area of Awaji island (Nakata et al., 1995). No clear surface trace was found in the eastern part of the source area around Kobe on Honshu island. Shimamoto (1995) presumed the area of JMA intensity VII corresponding to the faults, which generated the earthquake. On the other hand, aftershocks occurred close to existing Quaternary faults, which are located north of Kobe. Sekiguchi et al. (1996) identified three fault segments along the Rokko fault system using the particle motions of the strong-motion records and the geodetic data in the near-source region. Kamae et al.
(1998) and Kamae and Irikura (1998) simulated ground motions from the main shock by an empirical Green's function method using the asperity distribution on the fault founded by Sekiguchi et al. (1996). Their simulated ground motions agree well with the observed one. Based on simulated nearfault velocity in the frequency range of $0.1-1.0 \mathrm{~Hz}$, Sekiguchi et al. (2000) showed that the eastern end of the source was likely to have branched to the Gosukebashi and Ashiya faults. The precise fault location is still being investigated. In this study we adapted the fault model of Sekiguchi et al. (1996). One of the most important issues is whether the disaster resulted from unpredictable strong-ground motion or not. We address this issue in this study by analyzing the attenuation of the ground motion as a function of the closest distance to the fault.

Over 200 peak amplitudes of ground motion were observed during this earthquake. The main purpose of these observations was not to do research work but rather emergency response systems. Individual organizations that had strong-motion data kindly made their data available for this work. We investigated the records and the site conditions in detail. The sensors were installed on various ground conditions and some were located in seriously damaged areas. The observed peak-horizontal acceleration (PHA) and velocity 
(PHV) were compared with predicted values using attenuation relations developed in Japan (Fukushima and Tanaka, 1992: modified Fukushima and Tanaka, 1990; Midorikawa, 1993). Similar comparisons have been performed in other studies (e.g., Irikura and Fukushima, 1995; Ejiri et al. 1996; Midorikawa et al. 1996; Fukushima et al. 1997). In this study, the ratio of predicted to observed peak amplitude is newly studied for various ground conditions: (1) bedrock; (2) Neogene; (3) diluvium, which is the consolidated alluvium; (4) alluvium, which is unconsolidated; and (5) reclaimed ground. Further, the ratio of peak vertical acceleration (PVA) and velocity (PVV) to horizontal component is evaluated. The PHA/PHV and PVA/PVV ratios for various ground conditions are also studied.

At several sites close to the source, PVA was higher than PHA on soft soil ground. This phenomenon was previously observed at Array 6 in the 1979 Imperial Valley earthquake, and has been explained in terms of nonlinear behavior (Mohammadioun and Pecker, 1984). Clear nonlinear behavior has been identified in the Kobe event in vertical array records at Port Island, where the PVA at the surface was also larger than the horizontal component.

The determination of spatial distribution for PHA near fault is very important to know the strong ground motion characteristics in the near-source region. Some iso-PHA maps were determined from the observation PHAs only. However, these are usually difficult subjects because the determination of average function is almost equal to deriving a new attenuation relation, which must be applicable to the near source region (Stewart et al., 1994; Borcherdt and Holzer, 1996). Even if an attenuation relation could be used as the average function, the distribution of PHA was distorted in sparse observation area (Fukushima et al., 1998). Fortunately, the digital geological information furnished as the GIS (the Digital National Land Information compiled by the Geographic Survey Institute and the National Land Agency, Japan) around this area is available. We try to derive correction functions of the geological conditions and determine an iso-PHA map multiplying the predicted value by the attenuation relation and the correction function.

\section{Data}

Prior to this event, strong-motion data were disclosed by only a few observational organizations in Japan. After the Kobe event, however, all organizations kindly made their data available. Peak-ground accelerations and velocities from the event were announced immediately by the Railway Technical Research Institute (RTRI; Nakamura et al., 1995), Osaka Gas Co., Ltd., the Committee of Earthquake Observation and Research in the Kansai Areas (CEORKA), Kansai Electric Power Company (KEPCO), the Port and Harbor Research Institute (PHRI), the JMA, and others. A database of peak ground accelerations and velocities was compiled from these announcements and a prompt report was published by NIED (National Research Institute for Earth Science and Dis- aster Prevention, Science and Technology Agency, 1995). Digital records of strong-ground motions from this event were made available to the public by CEORKA (10 sites), JMA (14 sites), and the Port Island Strong Motion Station of the Development Bureau of Kobe city (four sites in a vertical array) within a few weeks. These data were compared with attenuation relations by Irikura and Fukushima (1995) and listed in Fukushima and Irikura (1997).

The catalog for strong-motion data of the earthquake was published by the Architectural Institute of Japan (1996) together with time histories, response spectrum, and particle orbits. The largest number of observation sites belongs to the Japan Railway Companies (JR), and their details were reported in Nakamura et al. (1996). The Conference on Usage of Earthquakes (CUE) in RTRI distributed five major records by floppy disks; this study is using the floppy disk with serial number R-031. The JMA distributed records taken by JMA87 type instruments through the Japan Weather Association. PHRI immediately released their records, and they were reported by Miyata et al. (1995). Records of the Public Works Research Institute (PWRI) of the Ministry of Construction, Hanshin Expressway Public Corporation, and Honshu-Shikoku Bridge Authority are announced in the Technical Note of PWRI (1995), and their digital data are distributed by floppy disks with the Technical Note. The Building Research Institute (BRI) of the Ministry of Construction reported their data in Kashima and Kitagawa (1995). CEORKA reported on observation records just after the event (Geo-Research Institute, Osaka, 1995). The Japan Society for Earthquake Engineering Promotion (1998) completed a database and distributed it on $\mathrm{CD}$ with a report. The CD contains data observed by Obayashi Corporation, Konoike Construction Co., Ltd., Maeda Corporation, KEPCO, Osaka Gas Co. Ltd., RWRI, BRI, PHRI, Ministry of Posts and Telecommunications, Hanshin Expressway Public Corporation, Kobe City Office, Shiga Prefecture, Laboratory of Strong Motion Seismology of DPRI, Research Center of Earthquake Prediction of DPRI of Kyoto University, Research Reactor Institute Kyoto University, and Shiga Prefecture University. Data from other organizations, such as the Ohsaka Technical Institute, Kansai University, NTT, Takenaka, Hankyu Railway, the Technical Institute of Matsumura-gumi, Kansai Airport and others, are listed by the Architectural Institute of Japan (1996). Further, Hokushin Railway, Nose Railway, and NHK announced their data individually.

These strong-motion instruments have been installed for various purposes, so their sensors were set up differently. We investigated the individual site condition of each instrument (Matsumoto et al., 1998). The investigated sites are listed in the appendix.

The peak acceleration and velocity data contain differential values from the velocity records and integral values from the accelerograms, respectively. Although the faultnormal component is already known to be very large in the near-fault region (Somerville et al., 1997), the orientation of 


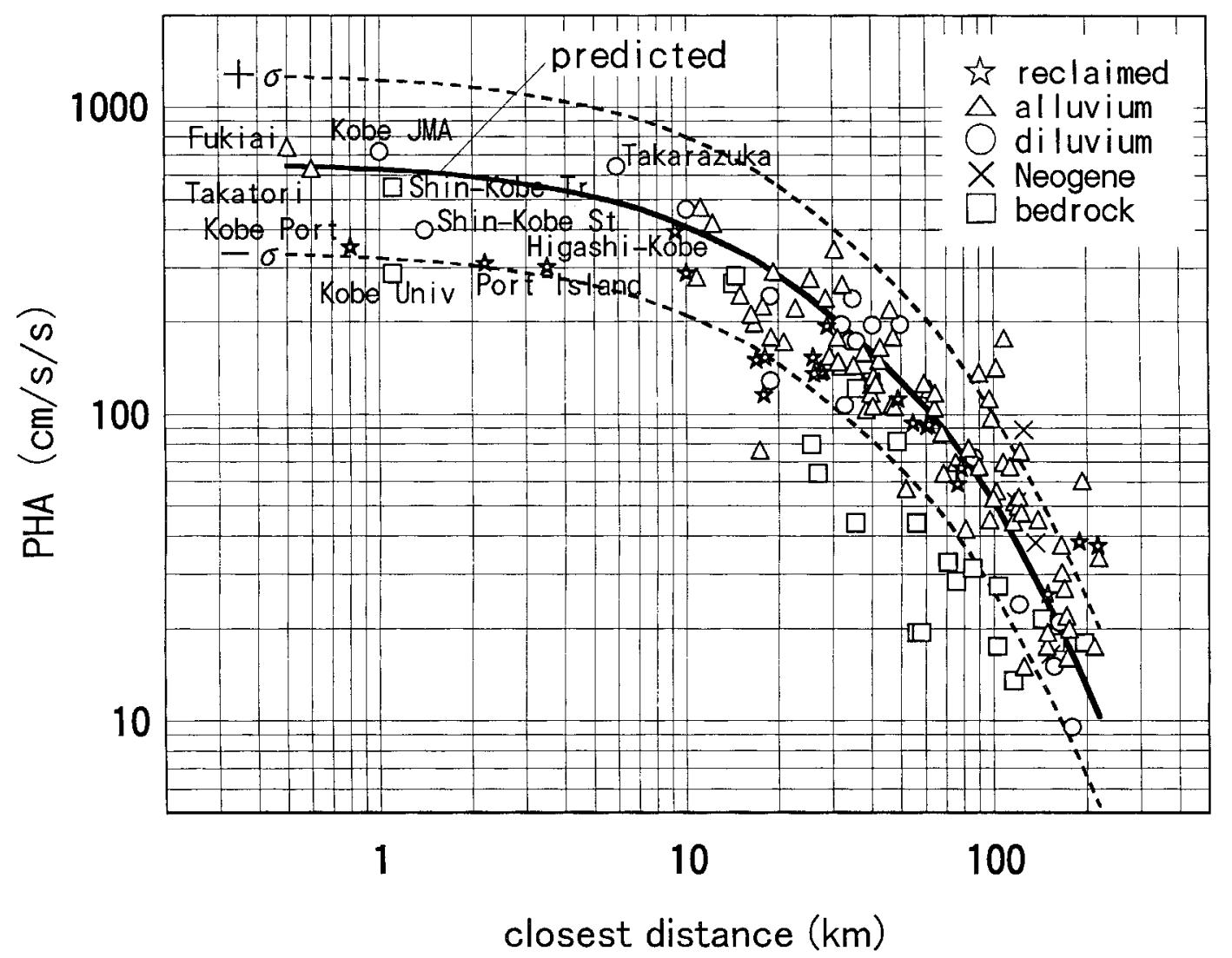

Figure 1. Comparison between observed peak-horizontal accelerations and the predicted values using empirical attenuation equation (1). Individual marks indicate different ground conditions at the observation site. The solid line indicates the predicted peak-horizontal acceleration. Broken lines indicate the standard error of the equation.

Table 1

Number of Data

\begin{tabular}{lrcrc}
\hline Category & PHA & PHV & PVA & PVV \\
\hline Bedrock & 22 & 21 & 22 & 19 \\
Neogene & 5 & $\uparrow$ & 4 & - \\
Diluvium & 18 & 13 & 16 & 10 \\
Alluvium & 76 & 45 & 68 & 39 \\
Reclaimed & 21 & 17 & 20 & 15 \\
All data & 142 & 96 & 130 & 83 \\
\hline
\end{tabular}

some sites is unknown; therefore, the mean peaks of two horizontal components are taken to be PHA and PHV. Data of only one horizontal component is rejected.

These mean values are more stable and only $10 \%$ smaller than the maximum values of the two corresponding horizontal components on average. A total of 142 PHA and 96 PHV observations were selected on the basis of the following conditions:

1. The sensor should be installed on free surface. Sensor located in structures such as buildings were excluded from the study.

2. Borehole instruments installed at a depth greater than 1 $\mathrm{m}$ for soil site and greater than few tens of meters for rock site are excluded in order to avoid the effect of the downgoing waves reflected at the ground surface.

3. Only large records are observed at far distance and biased on the average characteristics (Fukushima, 1997). Therefore the records at the distances less than $220 \mathrm{~km}$ are accepted. This is the reliability limit of the attenuation relation (Fukushima and Tanaka, 1990) for this magnitude.

The number of PVA and PVV records are 130 and 83, respectively; this number is smaller than the one for PHA, because the absence of vertical sensors at some sites. No surface trace was found in the eastern part of the fault, so it is difficult to precisely locate the fault plane. We assumed a single plane, simplifying the three-segment-fault model of Sekiguchi et al. (1996). The length, width, strike angle, and dip angle of the fault plane are assumed to be $45 \mathrm{~km}, 15 \mathrm{~km}$, 235 degrees, and 85 degrees, respectively. The shortest distance from the simplified fault model to the observation site is used for empirical predictions of peak amplitude in this study. Because fault distance errors are up to several hundred meters, estimated distances of less than $500 \mathrm{~m}$ were taken to be $500 \mathrm{~m}$. Ground conditions at individual observation 


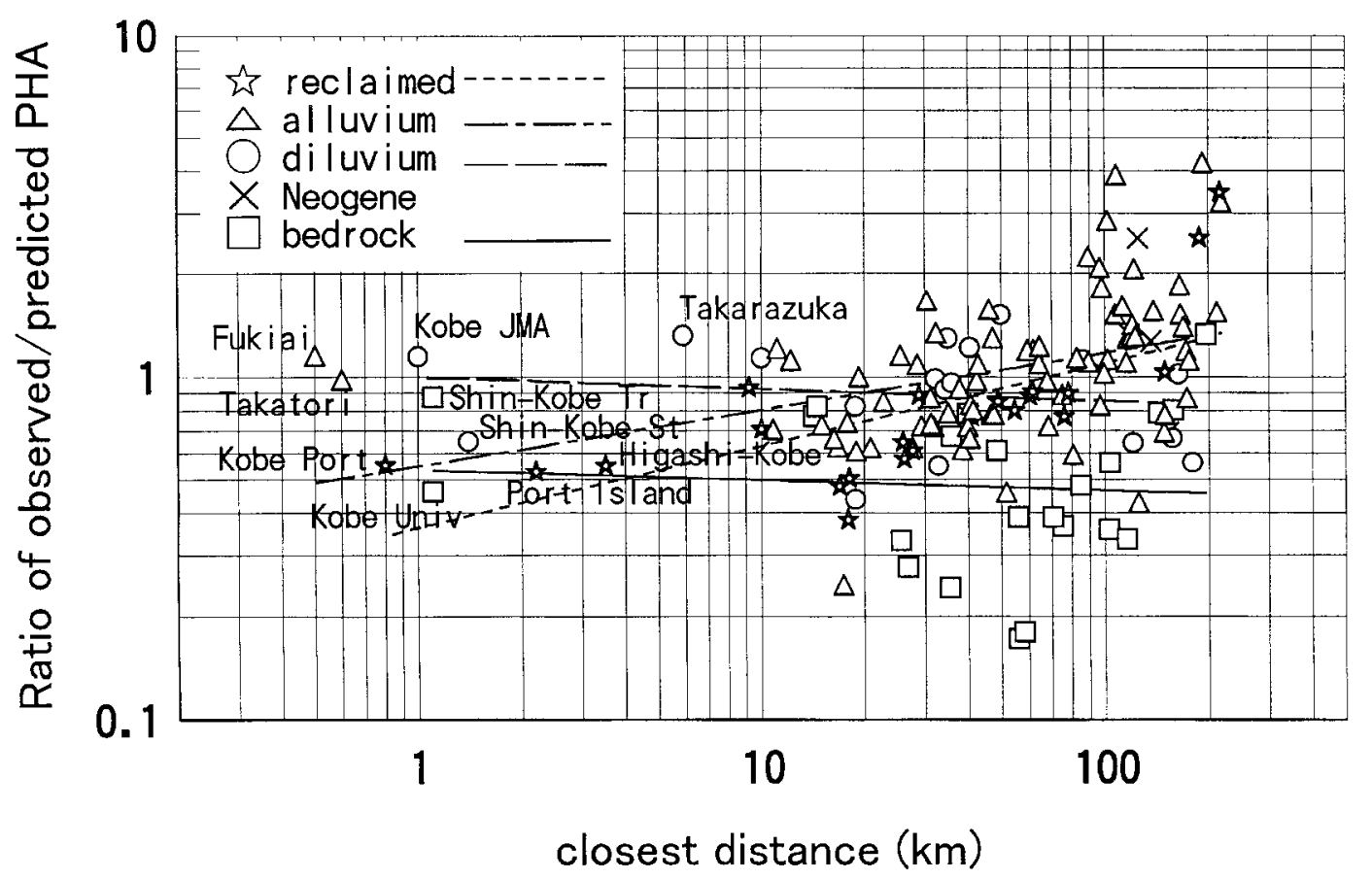

Figure 2. Relation between ratio of observed to predicted peak-horizontal acceleration and closest distance to the fault plane. Individual marks indicate different ground conditions at the observation site. Regression lines on the logarithmic scale are also indicated for the individual ground conditions.

Table 2

Ratios of Peak Amplitudes

\begin{tabular}{|c|c|c|c|c|c|c|}
\hline \multicolumn{3}{|c|}{ Average in linear scale } & \multirow[b]{2}{*}{ PVA/PHA } & \multirow[b]{2}{*}{ PVV/PHV } & \multirow[b]{2}{*}{ PHA/PHV } & \multirow[b]{2}{*}{$\begin{array}{l}\text { (PVA/PVV)/ } \\
\text { (PHA/PHV) }\end{array}$} \\
\hline Category & $\begin{array}{c}\text { Observed/Predicted } \\
\text { PHA }\end{array}$ & $\begin{array}{c}\text { Observed/Predicted } \\
\text { PHV }\end{array}$ & & & & \\
\hline Bedrock & 0.55 & 0.59 & 0.59 & 0.49 & 9.6 & 1.3 \\
\hline Neogene & few data & $\uparrow$ & 0.30 & - & - & - \\
\hline Diluvium & 0.94 & 0.78 & 0.46 & 0.38 & 13.5 & 1.3 \\
\hline Alluvium & distance dependent & 1.16 & 0.45 & 0.33 & 10.4 & 1.5 \\
\hline Reclaimed & distance dependent & 0.86 & 0.77 & 0.40 & 8.4 & 2.3 \\
\hline All data & 1.03 & 0.93 & 0.53 & 0.39 & 10.4 & 1.6 \\
\hline
\end{tabular}

sites were investigated from geological maps and logging data in the site vicinity and confirmed by visits to the site. Geological site conditions are classified into five types: (1) seismic bedrock, e.g., sedimentary rock predating the Neogene, and volcanic or plutonic rock; (2) Neogene strata; (3) diluvium; (4) alluvium; and (5) reclaimed ground. The number of data points in each category is indicated in Table 1 . There is only one observation of PHV on the Neogene, therefore, this data is included in the bedrock category.

\section{Attenuation Relations}

Fukushima and Tanaka (1990) collected 686 PHAs from 28 earthquakes in Japan and 15 earthquakes in the United States and other countries and used them to develop an attenuation relation by a two-step regression analysis. Later, new data of 147 PHAs were added and the attenuation relation was revised. The new result was almost the same as the previous one (Fukushima and Tanaka, 1992). This indicates that the derived empirical attenuation relation is very stable. The relation is given in the form of the following equation:

$$
\begin{aligned}
\log \text { PHA } & =0.42 M_{\mathrm{w}}-\log (R \\
& \left.+0.025 \times 10^{0.42 M_{\mathrm{w}}}\right)-0.0033 R+1.22
\end{aligned}
$$

where, PHA is in $\mathrm{cm} / \mathrm{sec}^{2}, M_{\mathrm{W}}$ is the moment magnitude, and $R$ is the distance from the fault plane to the site in $\mathrm{km}$. Ground conditions at the individual observation sites were not classified; therefore, this equation may be taken as corresponding to average ground conditions in Japan. 
Recently, a nonlinear scaling between earthquake ground motion and $M_{\mathrm{W}}$ has been recognized (Fukushima, 1996), particularly in the predominant period of several seconds, which is effective to PHV. In addition, a strong dependence on average $S$-wave velocity near the ground surface can be seen in PHV. Taking this nonlinear scaling and the dependence on $S$-wave velocity into account, Midorikawa (1993) developed the following attenuation relation for PHV:

$$
\begin{aligned}
\log \mathrm{PHV}=-0.22 M_{\mathrm{w}}^{2}+ & 3.94 M_{\mathrm{w}}-\log (R \\
+ & \left.0.01 \times 10^{0.43 M_{\mathrm{w}}}\right) \\
& -0.002 R-11.9 \\
& -0.71 \times \log V_{\mathrm{s}}
\end{aligned}
$$

where, PHV is in $\mathrm{cm} / \mathrm{sec}$ and $V_{\mathrm{S}}$ is the average $S$-wave velocity from the surface to $30 \mathrm{~m}$ deep in $\mathrm{m} / \mathrm{sec}$.

\section{Amplitude Ratios}

\section{Observed/Predicted}

Predicted PHA values from equation (1) are compared with the observed values in Figure 1. Most of the observed data points fall within the standard error of the attenuation relation, even if errors of several hundred meters in evaluating the distance from the fault are considered. The ratios of observed/predicted PHA are shown in Figure 2 with different marks for individual geological conditions. As shown in Table 2, the average ratios for bedrock and diluvium are 0.55 and 0.94 . At distance ranges over $100 \mathrm{~km}$, the ratios for alluvium and reclaimed ground are larger than 1.0 on average. On the contrary, the ratios for reclaimed ground and alluvium decrease with decreasing distance due to the nonlinear behavior of soils described in the next section. The following equations are adopted as the distance dependent ratios for the reclaimed ground and alluvium:

$$
\begin{aligned}
& \mathrm{O} / \mathrm{P}(\text { reclaimed })=0.362 \times R^{0.241} \\
& \mathrm{O} / \mathrm{P}(\text { alluvium })=0.549 \times R^{0.165}
\end{aligned}
$$

where $\mathrm{O} / \mathrm{P}$ is observed/predicted PHA ratio. Using these correction factors, the standard error decreases from 0.247 to 0.193 in base-ten logarithms. Further, if these distance dependencies are caused by nonlinear behavior, the level of PHA may affect the ratio. Figure 3 shows the relation between the ratio of observed to predicted PHA and the predicted PHA. The following relations between predicted PHA and the ratio are determined for reclaimed ground and alluvium:

$$
\begin{aligned}
& \mathrm{O} / \mathrm{P}(\text { reclaimed })=5.476 \times \mathrm{PHA}^{-0.383} \\
& \mathrm{O} / \mathrm{P}(\text { alluvium })=3.113 \times \mathrm{PHA}^{-0.239}
\end{aligned}
$$
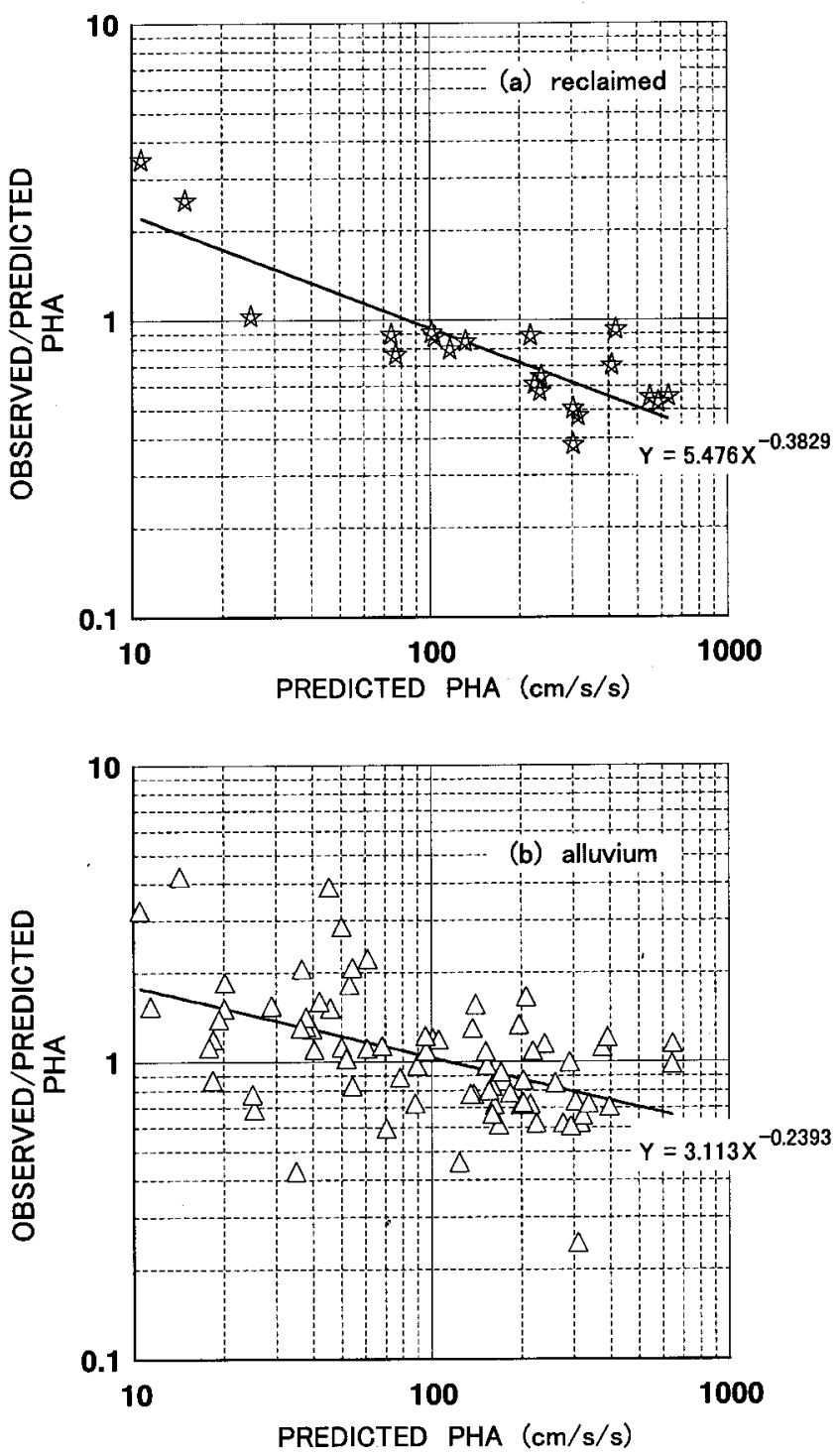

Figure 3. Relation between ratio of observed to predicted peak-horizontal acceleration and the predicted peak-horizontal acceleration for (a) reclaimed ground and (b) alluvium. Solid lines indicate regression lines for the data points.

Using these correction factors, the standard error decreases to 0.180 . Although it is limited to the case of the Hyogo-ken Nanbu event, this residual corresponds to a standard deviation from $66 \%$ to $151 \%$ for predicted PHA.

The comparison between observed and predicted PHVs is shown in Figure 4. In this figure, the prediction curves for the reference $S$-wave velocity (hereafter $V_{\mathrm{S}}$ ) of $400 \mathrm{~m} / \mathrm{sec}$, which is an average $V_{\mathrm{S}}$ of the database of Midorikawa (1993), as well as those for 200 and $700 \mathrm{~m} / \mathrm{sec}$ are indicated for a comparison of different values of $V_{\mathrm{S}}$. Equation (2) agrees well with the data. The ratios of observed/predicted PHV for the individual geological conditions are shown in Figure 5. As shown in Table 2, the ratios for stiff ground on average are small, for example, about 0.59 for bedrock and 


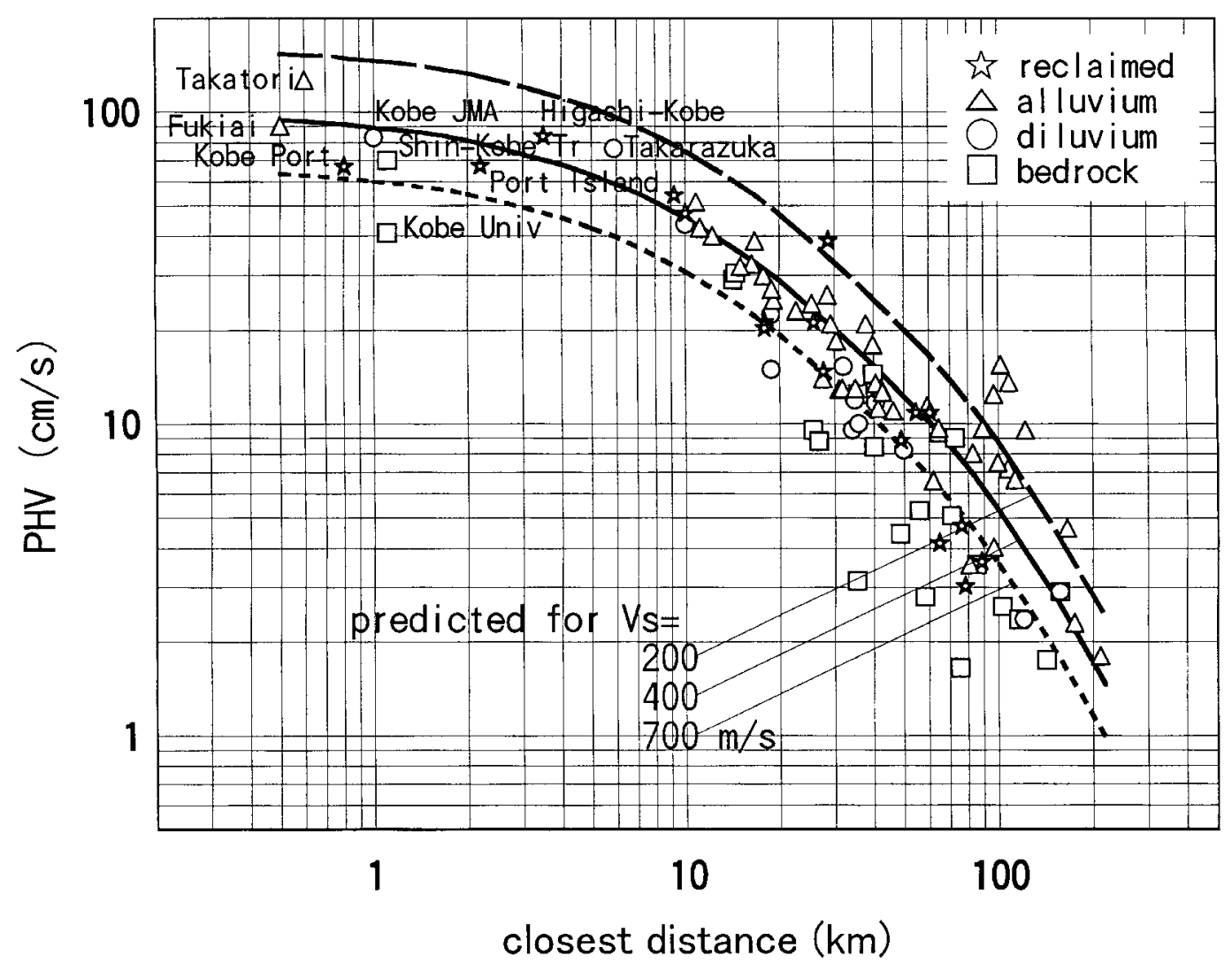

Figure 4. Comparison between observed peak-horizontal velocities and predicted levels using empirical attenuation equation (2). Individual marks indicate different ground conditions at the observation site. The predicted peak horizontal velocity for a reference $V_{\mathrm{S}}$ of $400 \mathrm{~m} / \mathrm{sec}$ is indicated by the solid line. The predicted velocities for other $V_{\mathrm{S}}$ of 200 and $700 \mathrm{~m} / \mathrm{sec}$ are also indicated by broken and chained lines, respectively.

0.78 for diluvium. The distance dependence seen in the case of PHA for soft soils cannot be seen in the case of PHV.

\section{Vertical/Horizontal}

The ratios of PVA/PHA are shown in Figure 6. In this figure, the dispersion in the data is too large to allow a systematic discussion. The average ratio is 0.53 as shown in Table 2. Most cases where the ratio is larger than 1.0 correspond with reclaimed ground or alluvium. All of these points are located near the seashore. This may be due to the effects of the nonlinear behavior, which was similarly observed during the 1979 Imperial Valley, California, earthquake (Mohammadioun and Pecker, 1984). Kawase et al. (1995) interpreted the remarkable decay of the horizontal components at the surface using effective stress analysis for the vertical array records at Port Island. Namely, the highfrequency horizontal component propagating as a shear wave was isolated by the liquefied soil. On the contrary, the high-frequency vertical component propagating as a compressional wave was amplified by the large contrast in $P$ wave velocity at the ground water level.

The ratios of PVV/PHV are shown in Figure 7. All ratios are less than 1.0 and their average is 0.39 . The ratios for bedrock seem to be larger than those for the other categories. This might be due to the large incident angle of $S V$ wave to the bedrock. However, even for bedrock, the average ratio is less than 0.5 . The peak acceleration correlates with the response spectral intensity of the predominant period from 0.2 to 0.8 seconds, whereas the peak velocity correlates with a relatively long period range from 0.5 to 1.5 seconds (Nakazawa et al., 1998). Therefore, the nonlinear behavior has less effect on the peak velocity than on acceleration.

\section{Acceleration/Velocity}

The average ratio of PHA/PHV for the observed data shown in Table 2 is 10. As shown in Figure 8, the individual ratios have a remarkable dependence on distance. The ratio peaks at around $50 \mathrm{~km}$. Values of PHA/PHV predicted from equations (1) and (2) are also shown in this figure. The curve of the predicted ratio has a similar characteristic. This fact indicates that the bend of attenuation curve for PHA is sharper than that for PHV around $50 \mathrm{~km}$. The observed ratios for soft soil in the distance range less than $10 \mathrm{~km}$ are small due to the decrease in PHA caused by the nonlinear behavior 


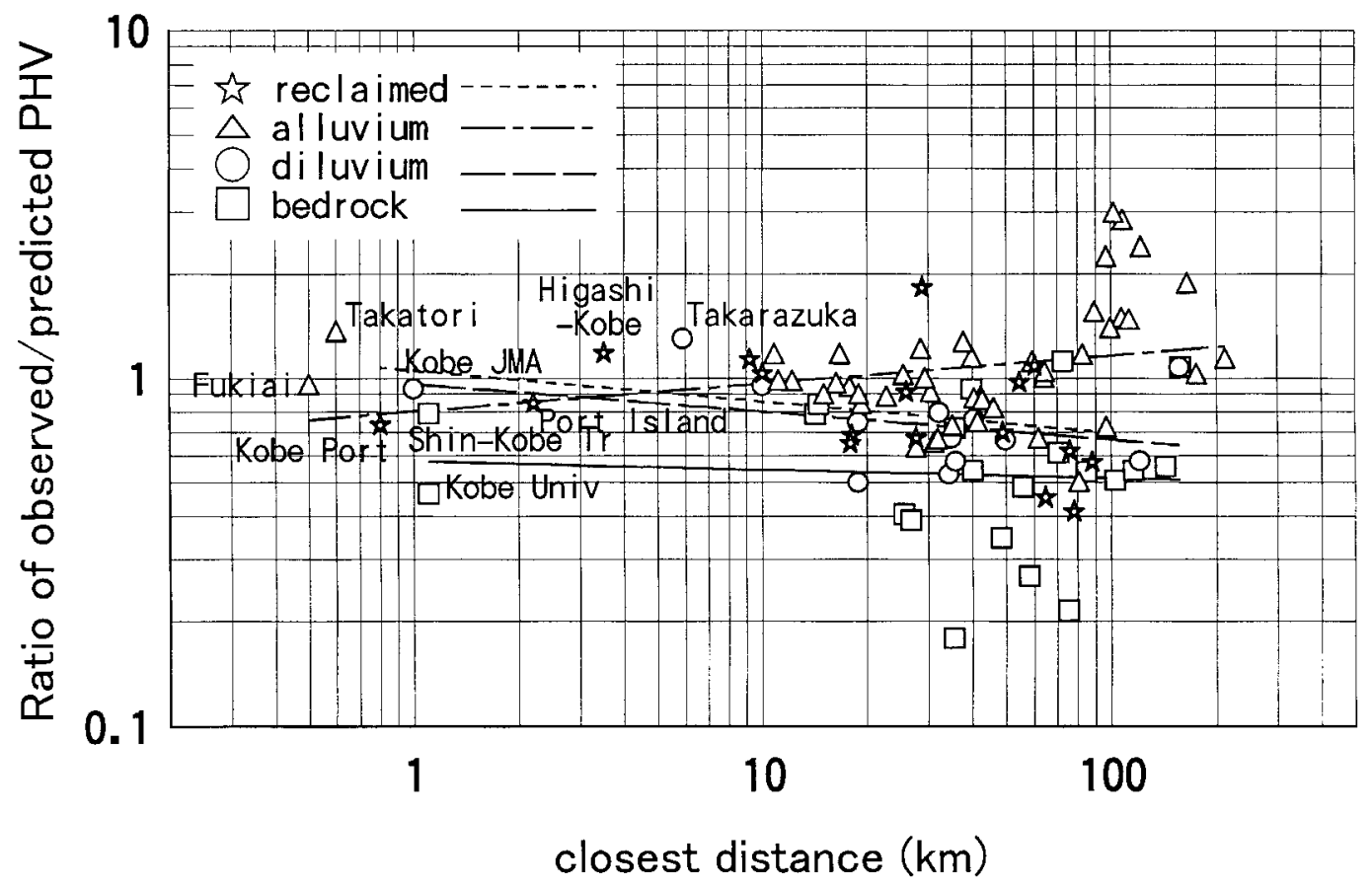

Figure 5. Relation between ratio of observed to predicted peak horizontal velocity for $V_{\mathrm{S}} 400 \mathrm{~m} / \mathrm{sec}$ and closest distance to the fault plane. Individual marks indicate different ground conditions at the observation site. Regression lines on the logarithmic scale are also indicated for the individual ground conditions.

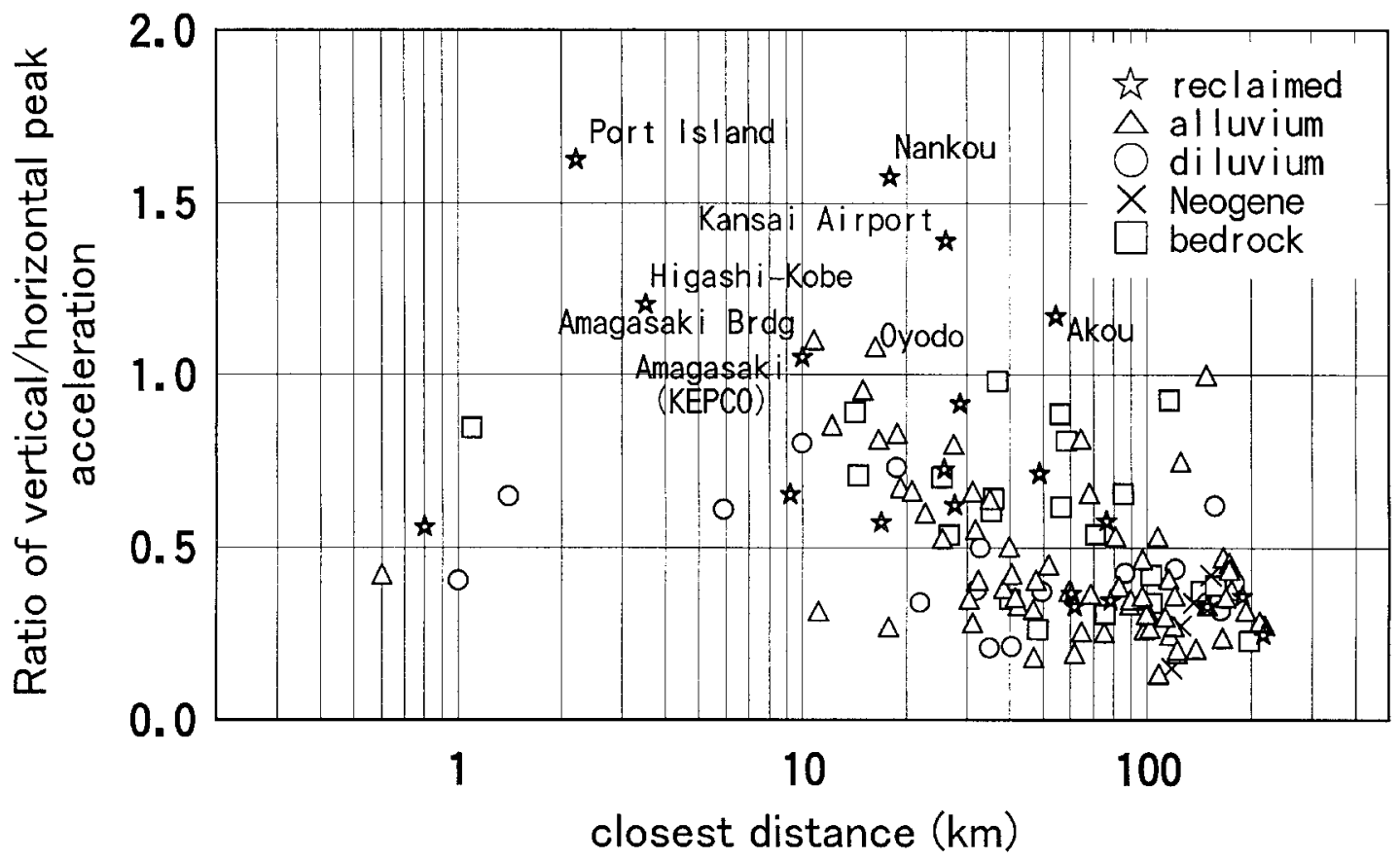

Figure 6. Relation between ratio of observed peak vertical per horizontal acceleration and distance. Individual marks indicate different ground conditions at the observation site. 


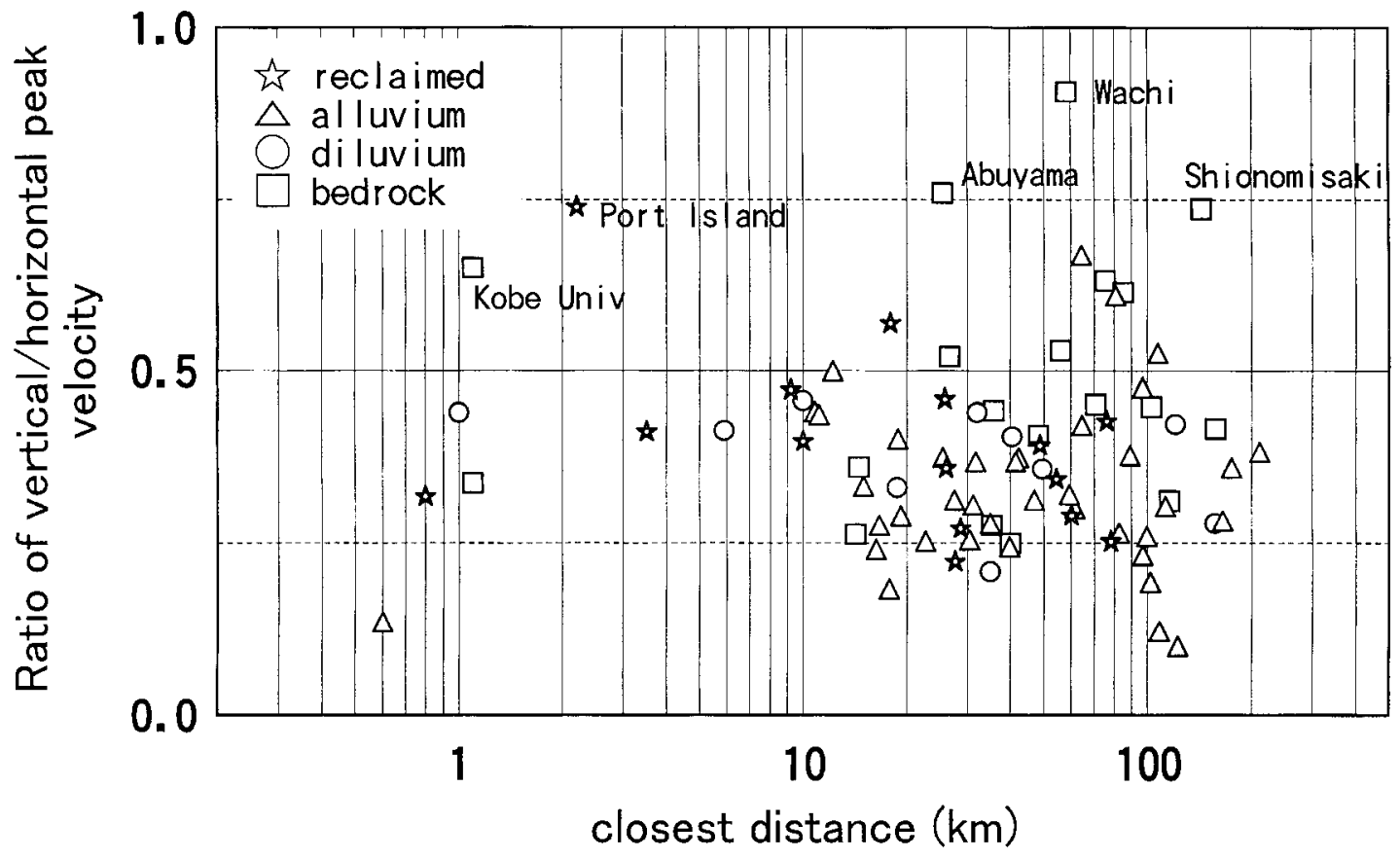

Figure 7. Relation between ratio of observed peak vertical to horizontal velocity and distance. Individual marks indicate different ground conditions at the observation site.

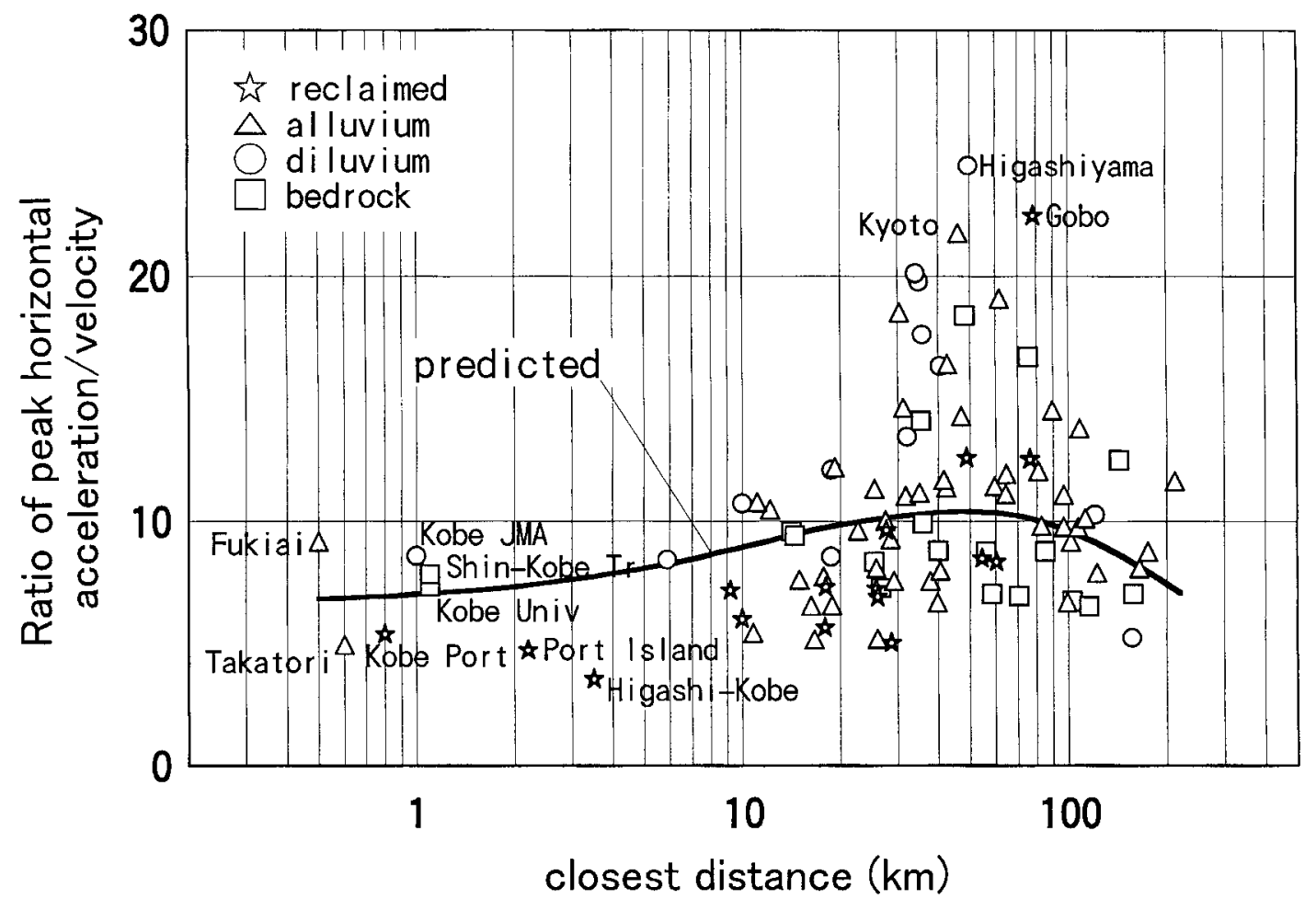

Figure 8. Ratio of peak-horizontal acceleration to velocity. Individual marks indicate different ground conditions at the observation site. Ratio predicted by the empirical attenuation relations of equations (1) and (2) is indicated by a solid line. 


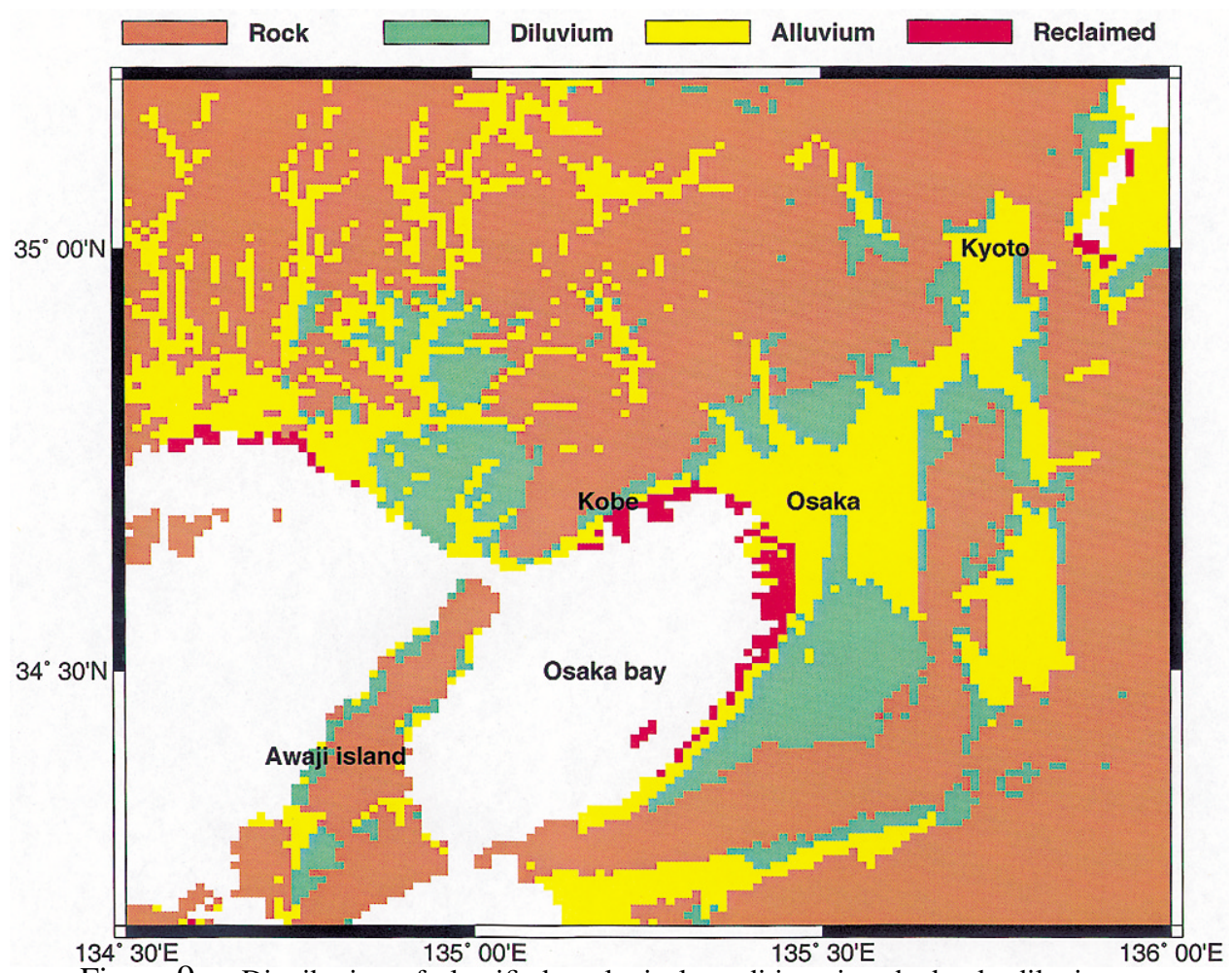

Figure 9. Distribution of classified geological conditions into bedrock, diluvium, alluvium, and reclaimed ground.

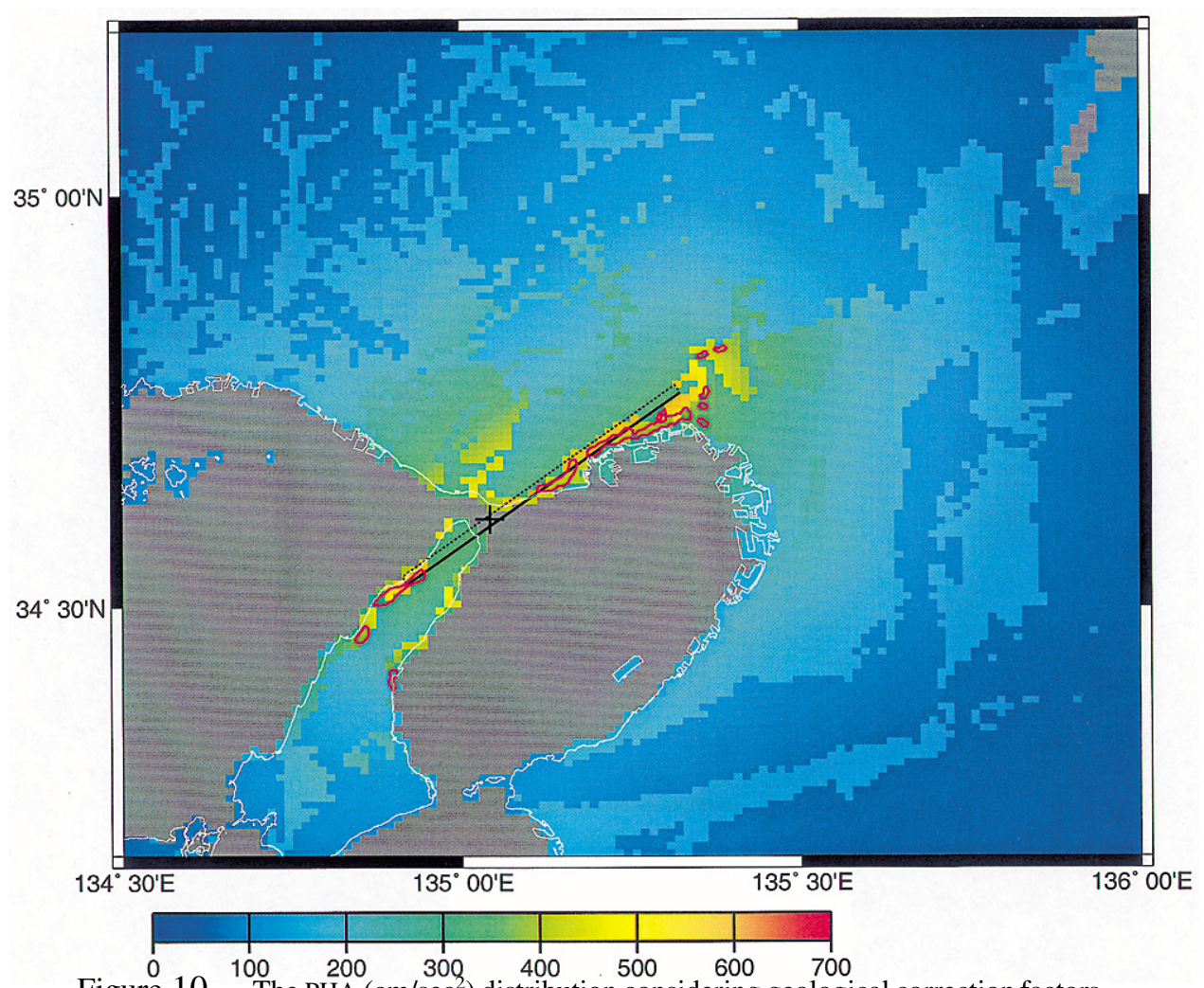

Figure 10. The PHA $\left(\mathrm{cm} / \mathrm{sec}^{2}\right)$ distribution considering geological correction factors for reclaimed, alluvium, diluvium, and bedrock. Long rectangle indicates assumed fault plane. Cross indicates epicenter. Areas indicated by red line depict the area of JMA intensity VII. 
of soils. On the other hand, PVA does not decrease as a result of the nonlinearity, so the ratios of PVA/PVV at short distances are larger than the PHA/PHV ratios, and the ratio of $(\mathrm{PVA} / \mathrm{PVV}) /(\mathrm{PHA} / \mathrm{PHV})$ for reclaimed ground is the largest in Table 2. If a frequency $f_{0} \mathrm{~Hz}$ predominated in the peak amplitude, at a first order approximation, the PHA can be expressed by $2 \pi f_{0}$ PHV. Therefore the mean value of 10 corresponds to the frequency of $1.6 \mathrm{~Hz}$. In the near-fault region, the ratio is about 7 and this corresponds to about 1 $\mathrm{Hz}$, which is consistent with predominant frequencies recorded at many sites near the causative faults. The ratio, which is related to the predominant frequency, for soft soils near the faults tends to further decrease due to the nonlinear behavior. On the contrary, sites of high ratio, for example Higashiyama and Kyoto, belong to areas of forward rupture directivity. Only Gobo is belonging to sideward directivity, but this site is located on thin reclaimed ground over bedrock, and high-frequency phases corresponding to reclaimed layers were predominant. At distances longer than $100 \mathrm{~km}$, the ratio falls off, perhaps due to the contamination caused by the low-frequency surface waves.

\section{Isoseismal Map}

The distribution of peak acceleration at the ground surface is very interesting, in particular the characteristics of strong-ground motion at near-fault sites where the number of observations was very limited. On the basis of the findings described in the previous section, we consider that equation (1) represents the average value of the PHA. We used GIS data on a fine grid points with the longitudinal and latitudinal interval of 0.0125 and 0.0083 degree around this area. The ground condition distribution is shown in Figure 9. This also includes the newly reclaimed area. The correction factors are estimated using equations (5) and (6) for the reclaimed and alluvial soil, and multiplying the average value by $55 \%$ and $94 \%$ for the bedrock and diluvium (Table 2). The surface PHA distribution was estimated by multiplying the predicted value of equation (1) and the correction factors for the completed distribution. In Figure 10, the estimated PHA is compared with the region of JMA intensity VII. Around the east end of the assumed fault plane, the area of the JMA intensity VII is located relatively south of the large PHA area. This divergence might be due to the basin edge effect that probably amplified the ground motion at sites along the basin edge, south of the fault (Kawase, 1996; Pitarka et al., 1998). However in general, the severe damage belt of the JMA intensity VII corresponds to the estimated high amplitude zone.

\section{Conclusions}

1. The 1995 Kobe earthquake caused severe structural damage in a modern metropolitan area. However, the observed peak amplitudes agree well with amplitudes pre- dicted by the empirical attenuation equations developed for Japanese earthquakes (Fukushima and Tanaka, 1992; Midorikawa, 1993), suggesting that on average the peak amplitude of the ground motion generated by the damaging earthquake did not exceed the level predicted by the empirical attenuation equation.

2. The ratio of the observed/predicted peak amplitudes for the average horizontal component significantly depends on the local ground conditions. The ratio is larger for soft soils, except for PHA at short distances, where the PHA decreases due to nonlinear behavior of soils. The residual between the observed and predicted PHA is considerably reduced if corrections for the site effect are applied.

3. The ratios of the PVA to PHA for soft soils are greater than 1.0 when PHA decreases as a result of the nonlinear behavior of soils. On the other hand, all of the PVV/PHV are less than 1.0, and are 0.4 on average.

4. The ratio of the PHA to PHV has a peak at around $50 \mathrm{~km}$. This demonstrates that the saturation of the PHA with decreasing distance in the near-source region is more notable than that of the PHV, in particular for soft soils.

5. The average correction factors for the individual geological conditions were derived from the ratio of the observed/predicted PHA. Multiplying the predicted PHA values by the attenuation relation and the correction factors, the PHA distribution reflecting also the effect of the surface geology can be derived for the near-fault region. The estimated high PHA area agrees well with the severe damage belt of the JMA intensity VII.

\section{Acknowledgments}

We wish to express our gratitude to all organizations that announced peak amplitudes and made observations available. Most kindly made their sites available to us. We also wish to express gratitude to Dr. Motofumi Watanabe of Shimizu Corp. for his suggestions in the writing of this manuscript and to Dr. Toshio Yamashita of TEPCO for his help in this research project. This manuscript was much improved by the rewriting of Dr. Arben Pitarka of URS Greiner Woodward Clyde Federal Services.

\section{References}

Architectural Institute of Japan (1996). 1995nen Hyogoken-Nanbu Jishin Kyoushin Kiroku Shiryousyu, January 1996, Special Working Group for Hyogoken-Nanbu Jishin, AIJ (in Japanese).

Borcherdt, R., and T. Holzer (1996). The January 17, 1995 HyogokenNanbu (Kobe) earthquake, performance of structures, lifelines, and fire protection systems, in Seismology, Geology, and Geotechnical Issues, Natl. Inst. Stand. Technol. Spec. Publ. 901, (Editor), R. Chung.

Eriji, J., S. Sawada, Y. Goto, and K. Toki (1996). Peak ground motion characteristics, Special Issue of Soils and Foundations, Japanese Geotechnical Soc., 7-13.

Fukushima, Y., and T. Tanaka (1990). A new attenuation relation for peak 
horizontal acceleration of strong earthquake ground motion in Japan, Bull. Seism. Soc. Am. 80, 757-783.

Fukushima, Y., and T. Tanaka (1992). Revised attenuation relation of peak horizontal acceleration by using a new data base, Programme and Abstracts of the Seism. Soc. Japan, No. 2, 116 (in Japanese).

Fukushima, Y. (1996). Scaling relations for strong ground motion prediction models with $M^{2}$ terms, Bull. Seism. Soc. Am. 86, 329-336.

Fukushima, Y. (1997). Comment on "Ground motion attenuation relations for subduction zones," Seism. Res. Lett. 68, 947-949.

Fukushima, Y., T. Watanabe, T. Uetake, and H. Matsumoto (1997). Attenuation characteristics of observed peak amplitude from 1995 Hyogoken Nanbu event, 14th SMiRT K02/5, 83-90.

Fukushima, Y., and K. Irikura (1997). Attenuation characteristics of peak ground motions in the 1995 Hyogo-ken Nanbu earthquake, J. Phys. Earth 45, 135-146.

Fukushima, Y., T. Watanabe, T. Uetake, and H. Matsumoto (1998). Characteristics of peak amplitude for strong ground motion from 1995 Hyogoken nanbu earthquake, in Proc of the 2nd International Symposium on the Effects of Surface Geology on Seismic Motion, 11551162.

Geo-Research Institute, Osaka (1995). Heisei 7-nen Hyogoken Nanbu Jishin Sokuhou, February, 1995 (in Japanese).

Irikura, K., and Y. Fukushima (1995). Attenuation characteristics of peak amplitude in the Hyogoken-Nambu earthquake, J. Natural Disaster Sciences, 16,(3), 39-46.

Japan Society for Earthquake Engineering Promotion (1998). Strong Motion Array Observation No. 3 (in Japanese).

Kamae, K., K. Irikura, and A. Pitarka (1998). A technique for simulating strong ground motion using hybrid Green's function, Bull. Seism. Soc. Am. 88, 357-367.

Kamae, K., and K. Irikura (1998). Source model of the 1995 Hyogo-ken Nanbu earthquake and simulation of near-source ground motion, Bull. Seism. Soc. Am. 88, 400-412.

Kashima, T., and Y. Kitagawa (1995). The 1995 Hyogo-ken-nanbu Earthquake, Prompt Report on Strong Motion Records, 4, Building Res. Inst., Ministry of Construction, Japan (in Japanese).

Kawase, H., T. Satoh, K. Fukutake, and K. Irikura (1995). Borehole records observed at the Port Island in Kobe during the Hyogo-ken Nanbu earthquake of 1995 and its simulation, J. Struct. Constr. Eng., AIJ, No. 475, 83-92 (in Japanese).

Kawase, H. (1996). The cause of the damage belt in Kobe: "the basin-edge effect", constructive interference of the direct $S$-wave with the basininduced diffracted/Rayleigh wave, Seism. Res. Lett. 67, 25-34.

Kikuchi, M. (1995). Teleseismic analysis of the Southern Hyogo (Kobe), Japan, earthquake of January 17, 1995, Yokohama City Univ. Seismological Note 38.

Matsumoto, H., T. Uetake, Y. Fukushima, and T. Watanabe (1998). Site effect for the attenuation characteristics of observed peak amplitude from 1995 Hyogo-ken Nanbu event, Proc. of the 10th Japan Earthquake Engineering Symposium 1, 541-546 (in Japanese).

Midorikawa, S. (1993). Preliminary analysis for attenuation of peak ground velocity on stiff site, Proc. of the International Workshop on Strong Motion Data, 2, 39-48.

Midorikawa, S., H. Si, and M. Matsuoka (1996). Empirical analysis of peak horizontal velocity for the Hyogo-ken Nanbu, Japan earthquake of January 17, 1995, Proc. of the 11th World Conference on Earthquake Engineering 1564, disk 3 of 4.

Miyata, M., Y. Satho, and S. Iai (1995). Mechanism of damage to port facilities during 1995 Hyogo-ken Nanbu earthquake (Part 1)—strongmotion earthquake records in port areas, Technical Note, The Port and Harbour Research Institute, Ministry of Transport, Japan, 813 (in Japanese).

Mohammadioun, B., and A. Pecker (1984). Low-frequency transfer of seismic energy by superficial soil deposits and soft rocks, Earthquake Eng. Struct. Dyn. 12, 537-564.

Nakamura, Y., K. Hidaka, J. Saita, and S. Sato (1995). Strong accelerations and damage of the 1995 Hyogoken-Nanbu earthquake, JR Earthquake Information No. 23b, Railway Technical Research Institute.

Nakamura, Y., F. Uehan, and H. Inoue (1996). Waveform and its analysis of the 1995 Hyogo-Ken-Nanbu earthquake (II), JR Earthquake Information No. 23d, Railway Technical Research Institute (in Japanese).

Nakata, T., K. Yomogida, J. Odaka, T. Sakamoto, K. Asahi, and N. Chida (1995). Surface fault ruptures associated with the 1995 HyogokenNanbu earthquake, J. Geography 104, 127-142.

Nakazawa, M., T. Uetake, H. Inada, T. Watanabe, and Y. Fukushima (1998). Relation between peak amplitude and response spectrum of strong ground motion from Hyogo-ken Nanbu earthquake, Summaries of Technical Papers of the Annual Meeting of the Architectural Institute of Japan B-2, 129-130 (in Japanese).

National Research Institute for Earth Science and Disaster Prevention, Science and Technology Agency (1995). Prompt Report on StrongMotion Accelerograms No. 46, January 17, 1995, Southern Hyogo Prefecture, Japan (in Japanese).

Pitarka, A., K. Irikura, T. Iwata, and H. Sekiguchi (1998). Three-dimensional simulation of the near-fault ground motion for the 1995 Hyogoken Nanbu (Kobe), Japan, earthquake, Bull. Seism. Soc. Am. 88, 428 440.

Public Works Research Institute (1995). Strong-motion acceleration records from public works in Japan (No. 21), Technical Note of Public Works Research Institute, Ministry of Construction, Japan, 64.

Sekiguchi, H., K. Irikura, T. Iwata, Y. Kakehi, and M. Hoshiba (1996). Minute locating of faulting beneath Kobe and waveform inversion of the source process during the 1995 Hyogo-ken Nanbu, Japan, earthquake using strong ground motion records, J. Phys. Earth 44, 473 448.

Sekiguchi, H., K. Irikura, and T. Iwata (2000). Fault Geometry at the 1995 Hyogo-ken Nanbu earthquake, Bull. Seism. Soc. Am. 90, 117-133.

Shimamoto, T. (1995). Mystery of "damage belt" during Kobe earthquake, Iwanami-Kagaku 65, No. 4, 195-198 (in Japanese).

Somerville, P. G., N. F. Smith, R. W. Graves, and N. A. Abrahamson (1997). Modification of empirical strong ground motion attenuation relations to include the amplitude and duration effects of rupture directivity, Seism. Res. Lett. 68, 199-222.

Stewart, J. P., J. D. Bray, R. G. Seed, and N. Sitar (1994). Preliminary report on the principal geotechnical aspects of the January 17, 1994, Northridge earthquake, Earthquake Engineering Research Center Report No. UCB/EERC 94/08, University of California, Berkeley.

Ohsaki Research Institute

Fukoku-seimei BLDG 27F

2-2-2, Uchisaiwai-cho

Chiyoda-ku, 1000011, Tokyo

Japan

yf@ori.shimz.co.jp

(Y. F.)

Disaster Prevention Research Institute

Kyoto University

Gokasho, Uji, 6110011

Japan

(K. I.)

Power Eng. R\&D Center

Tokyo Electric Power Company

4-1 Egasaki-cho, Tsurumi-ku

Yokohama, 2308510

Japan

(T. U., H. M.)

Manuscript received 24 May 1999. 


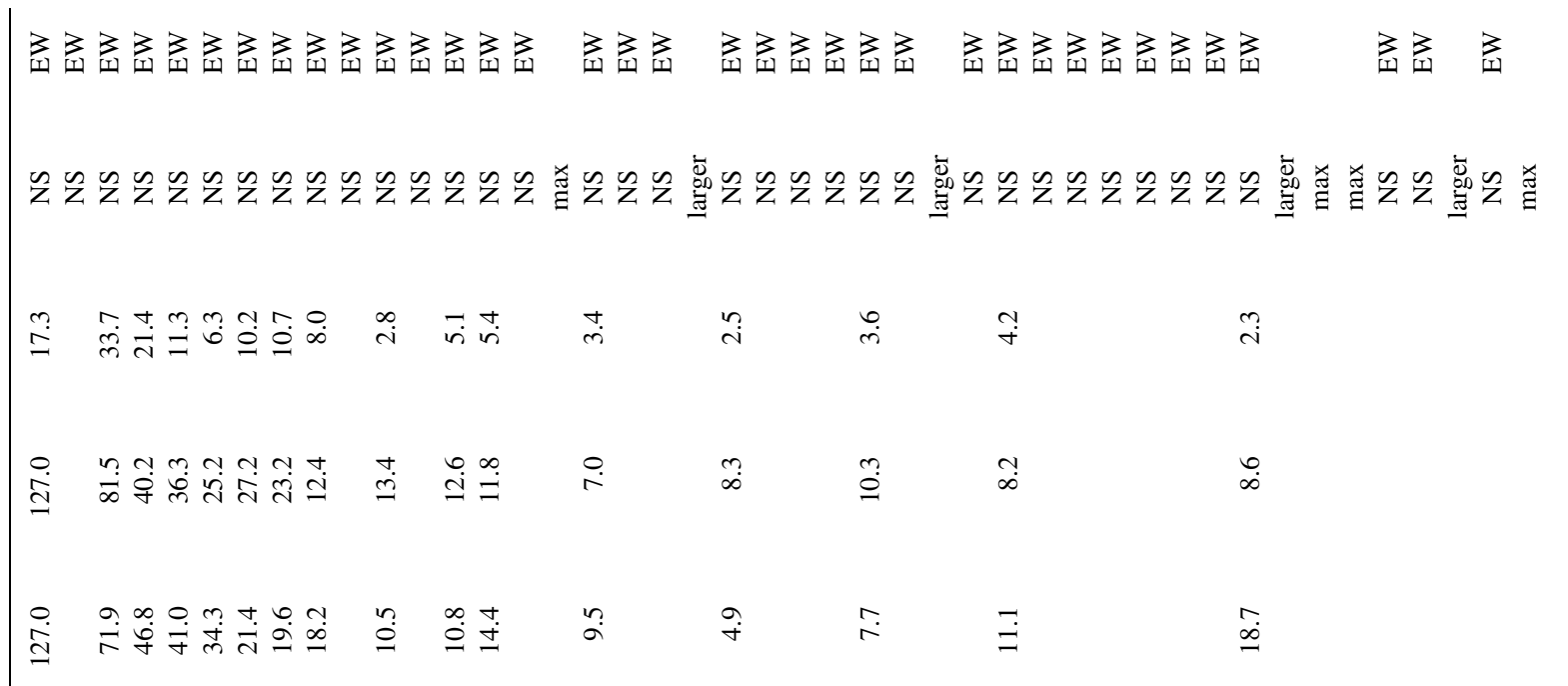

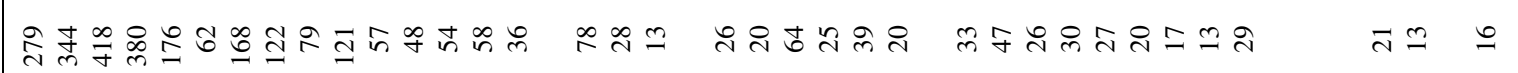

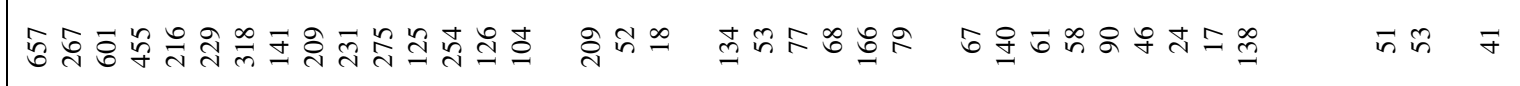

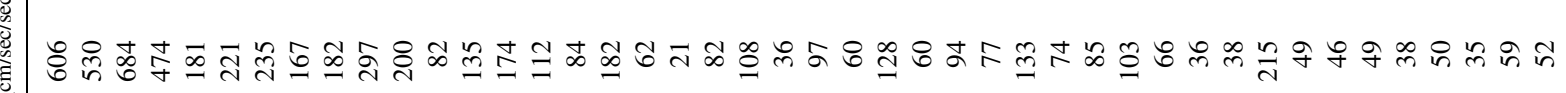

(3)

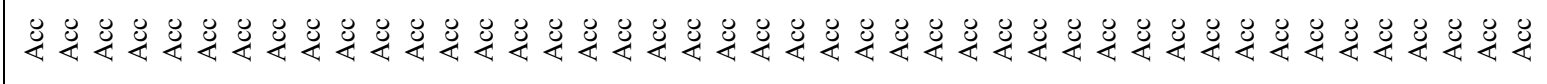

거

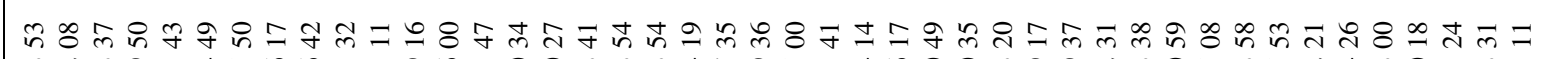

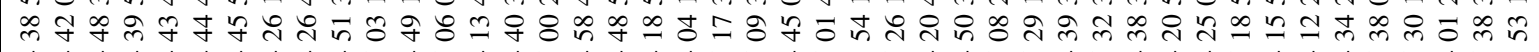

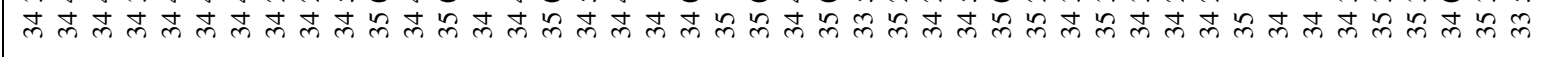

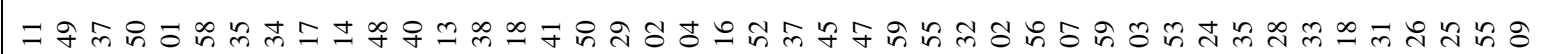

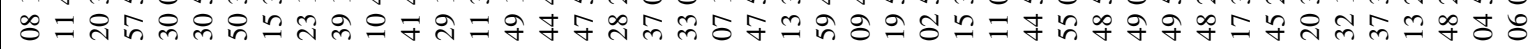

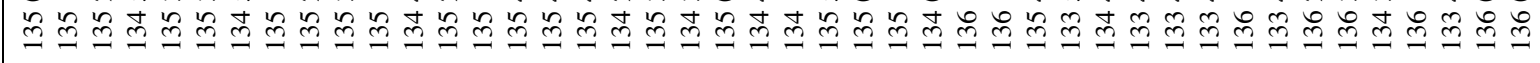

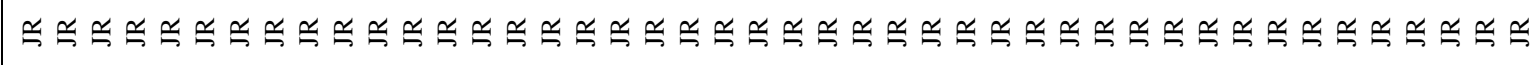

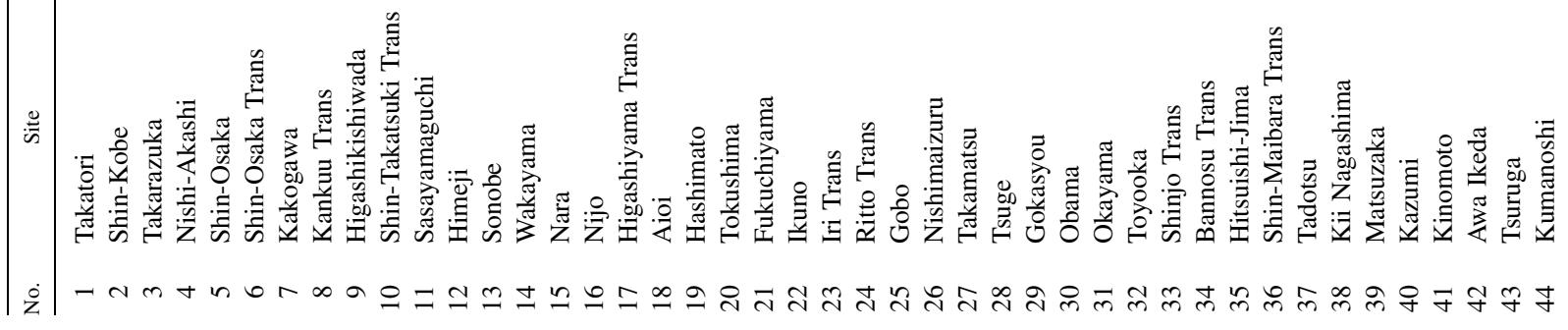




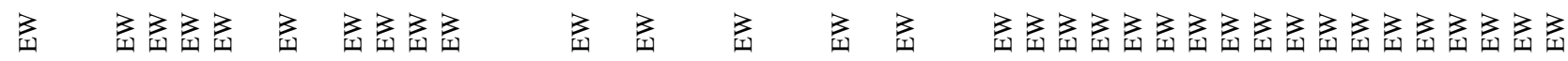

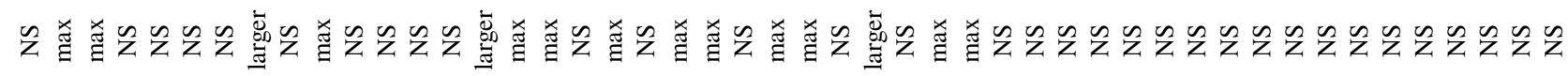

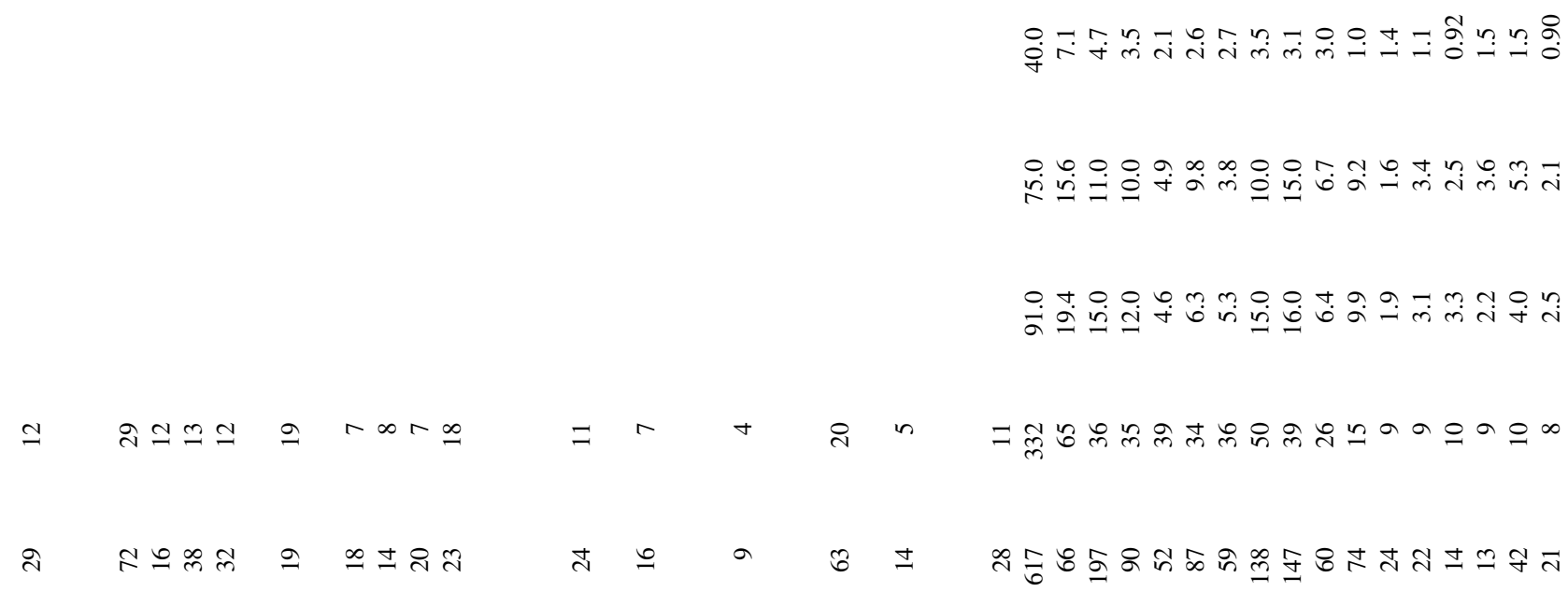

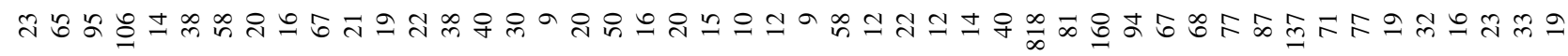

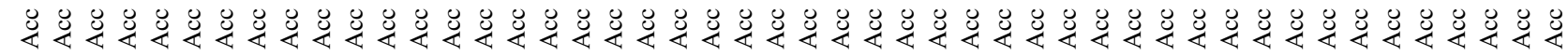
ગ

แำ

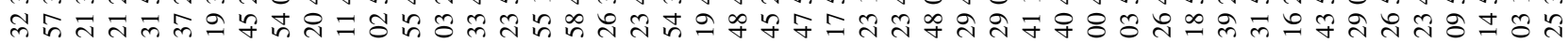

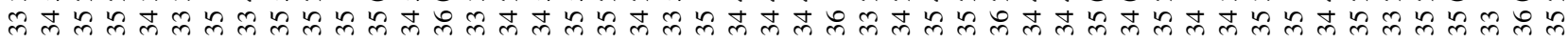

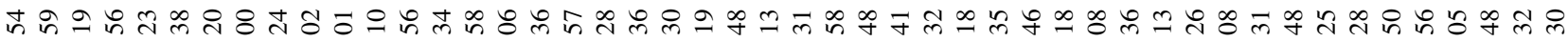

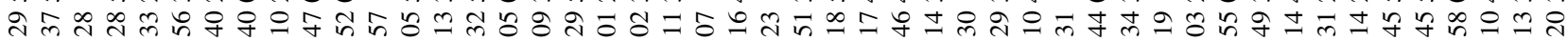

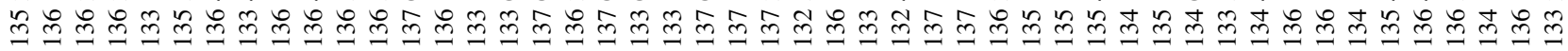

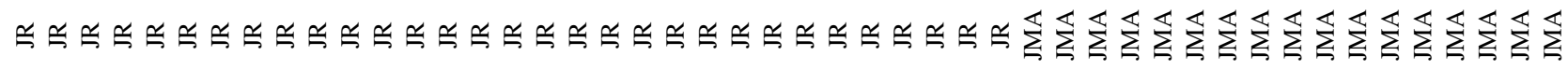

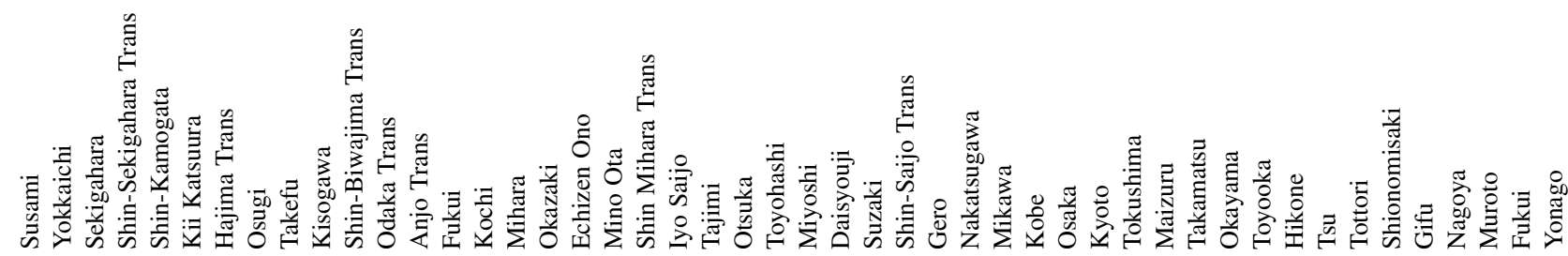

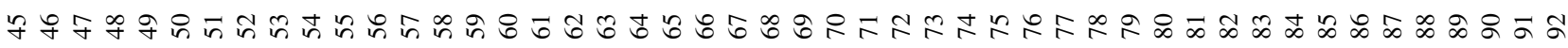




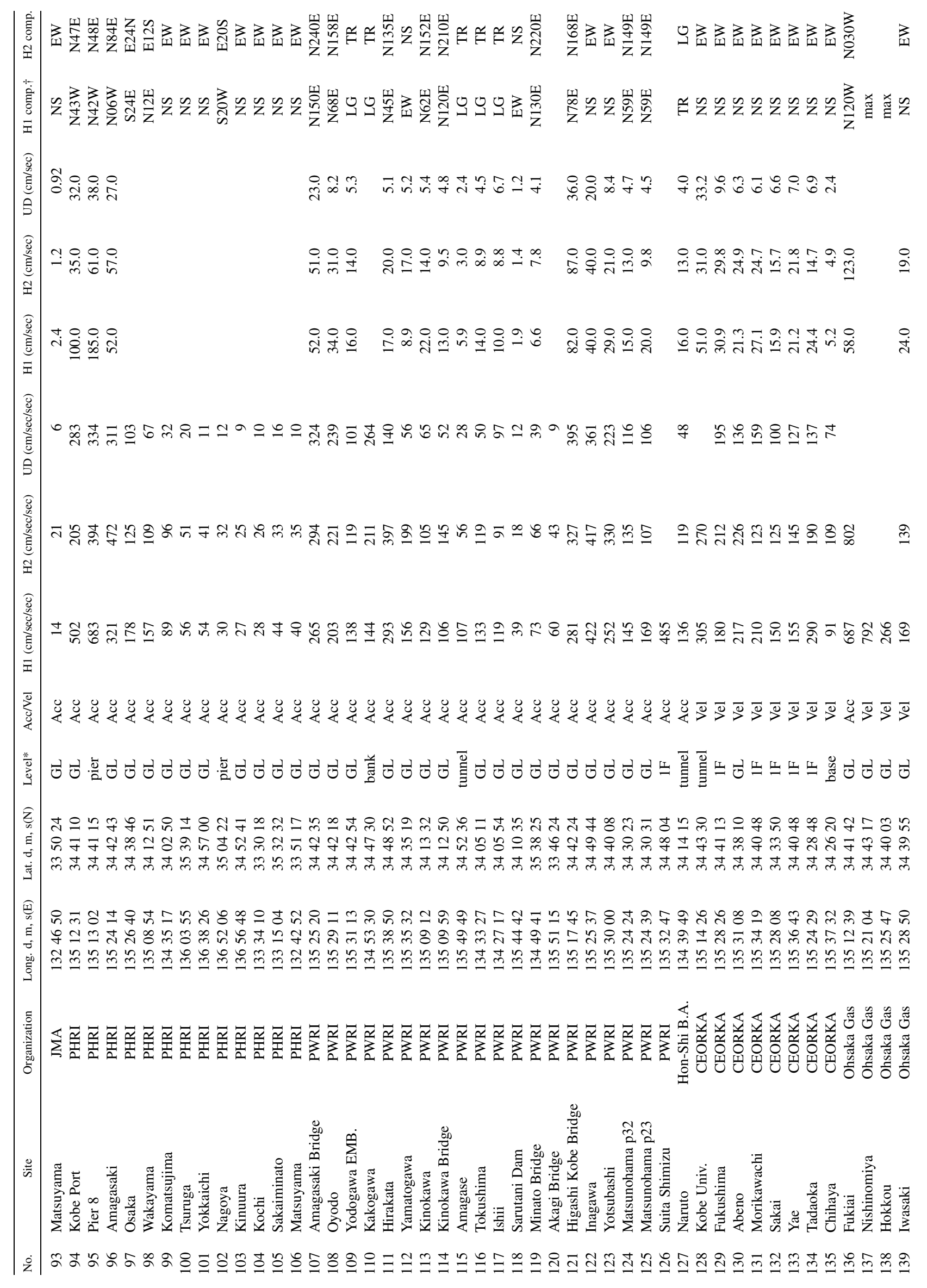




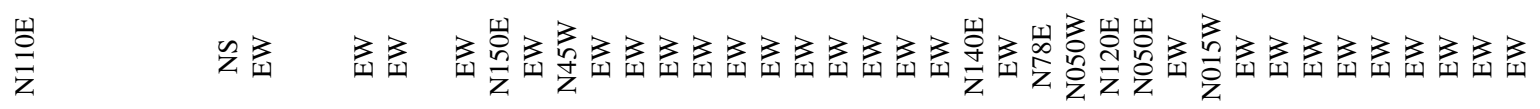

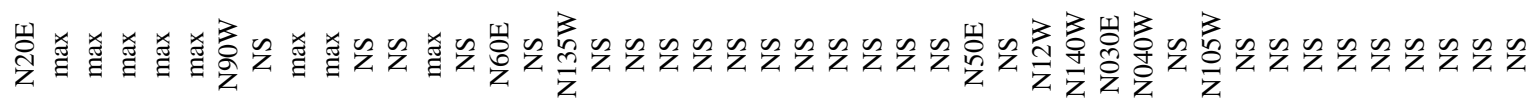

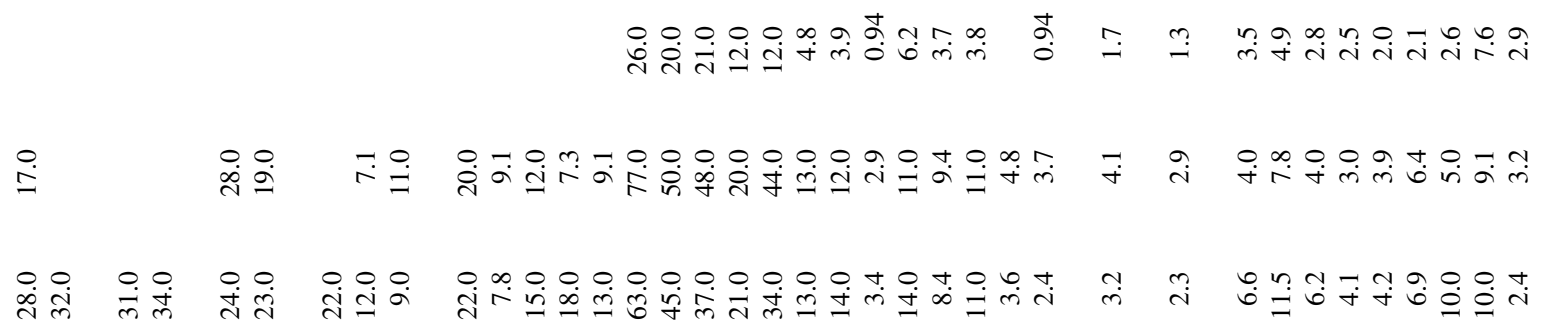

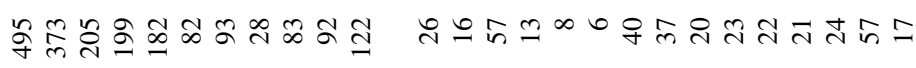

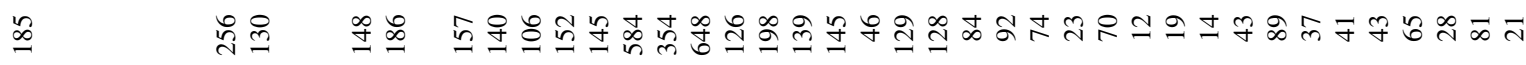

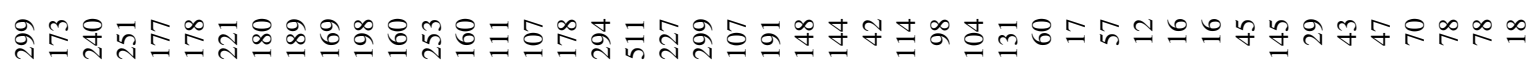

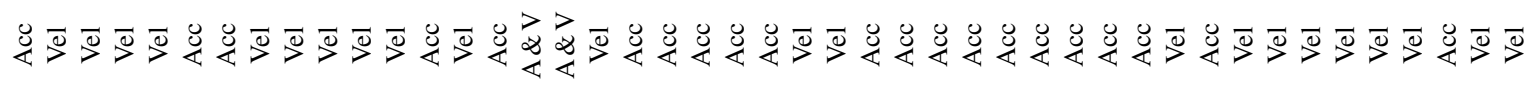

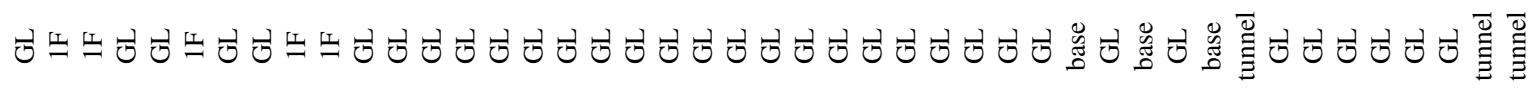

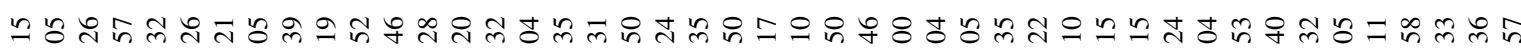

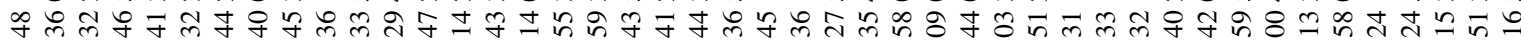

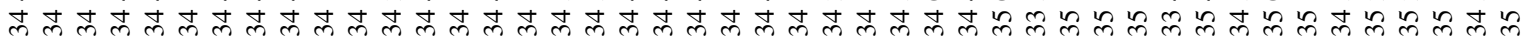

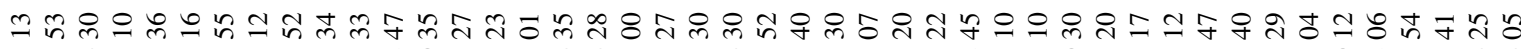

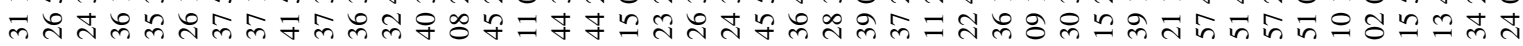

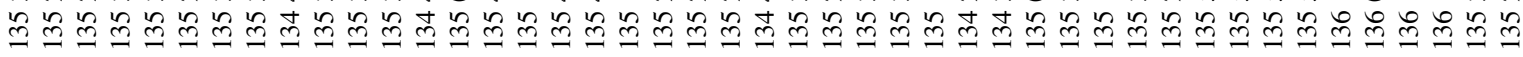

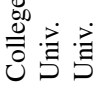

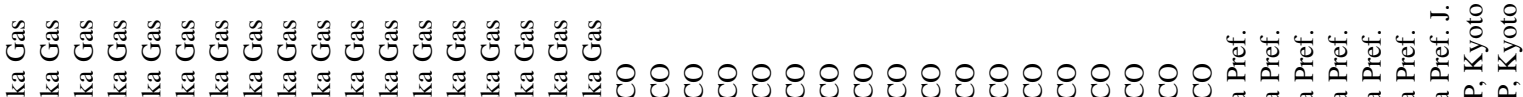

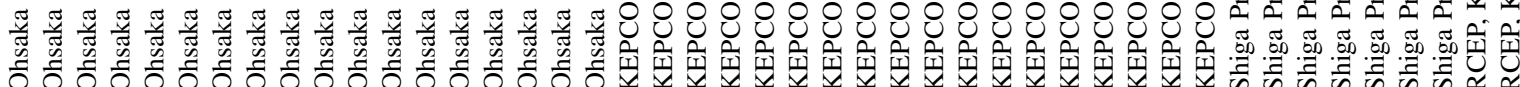

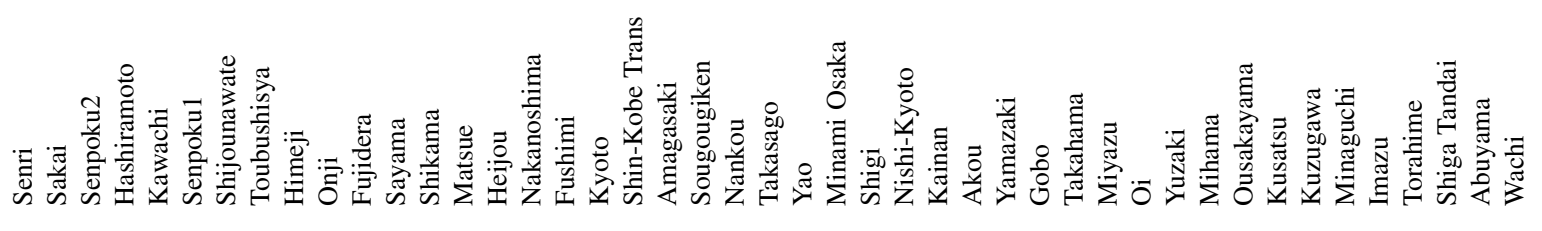

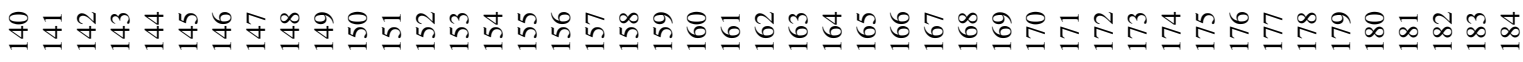




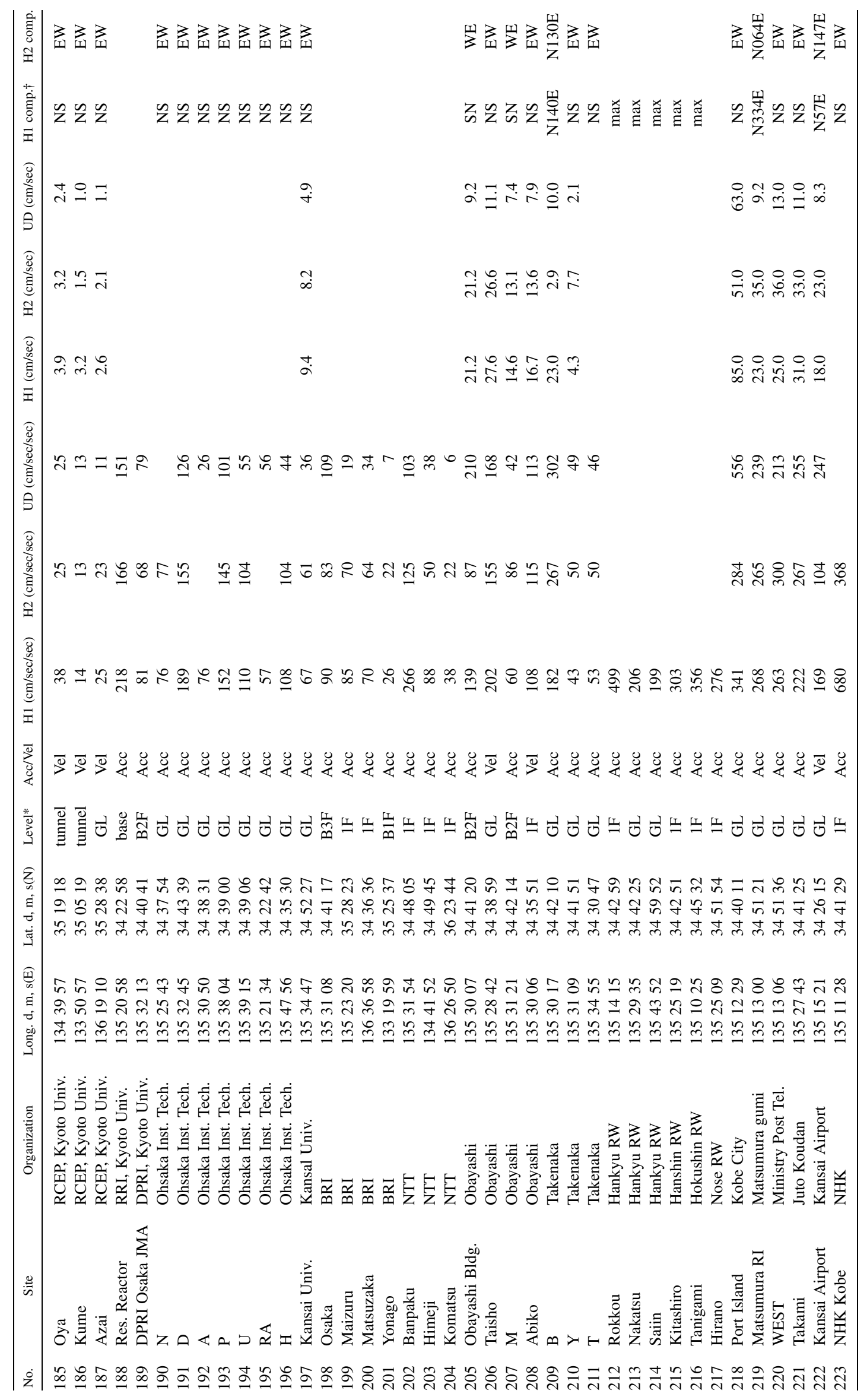




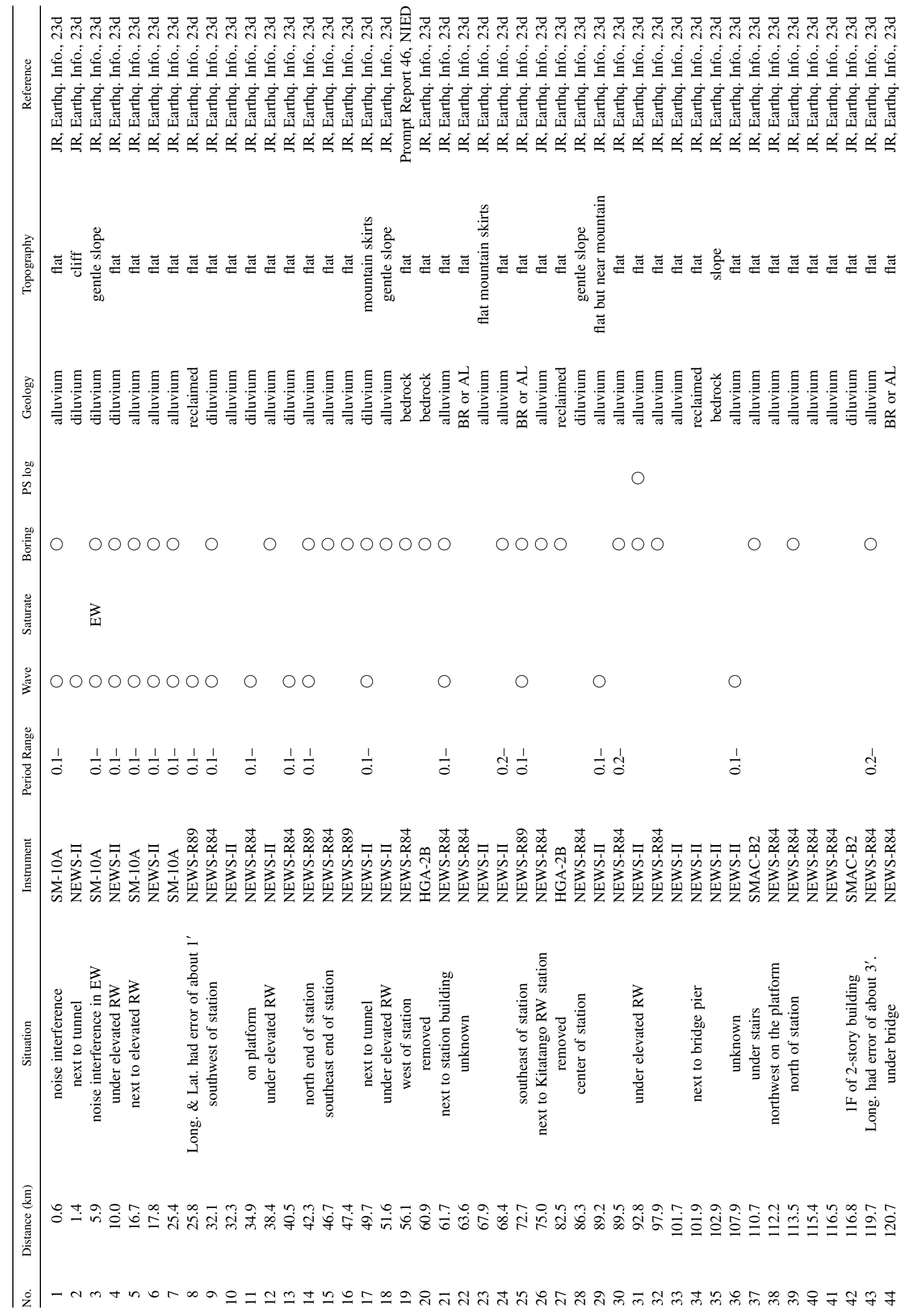




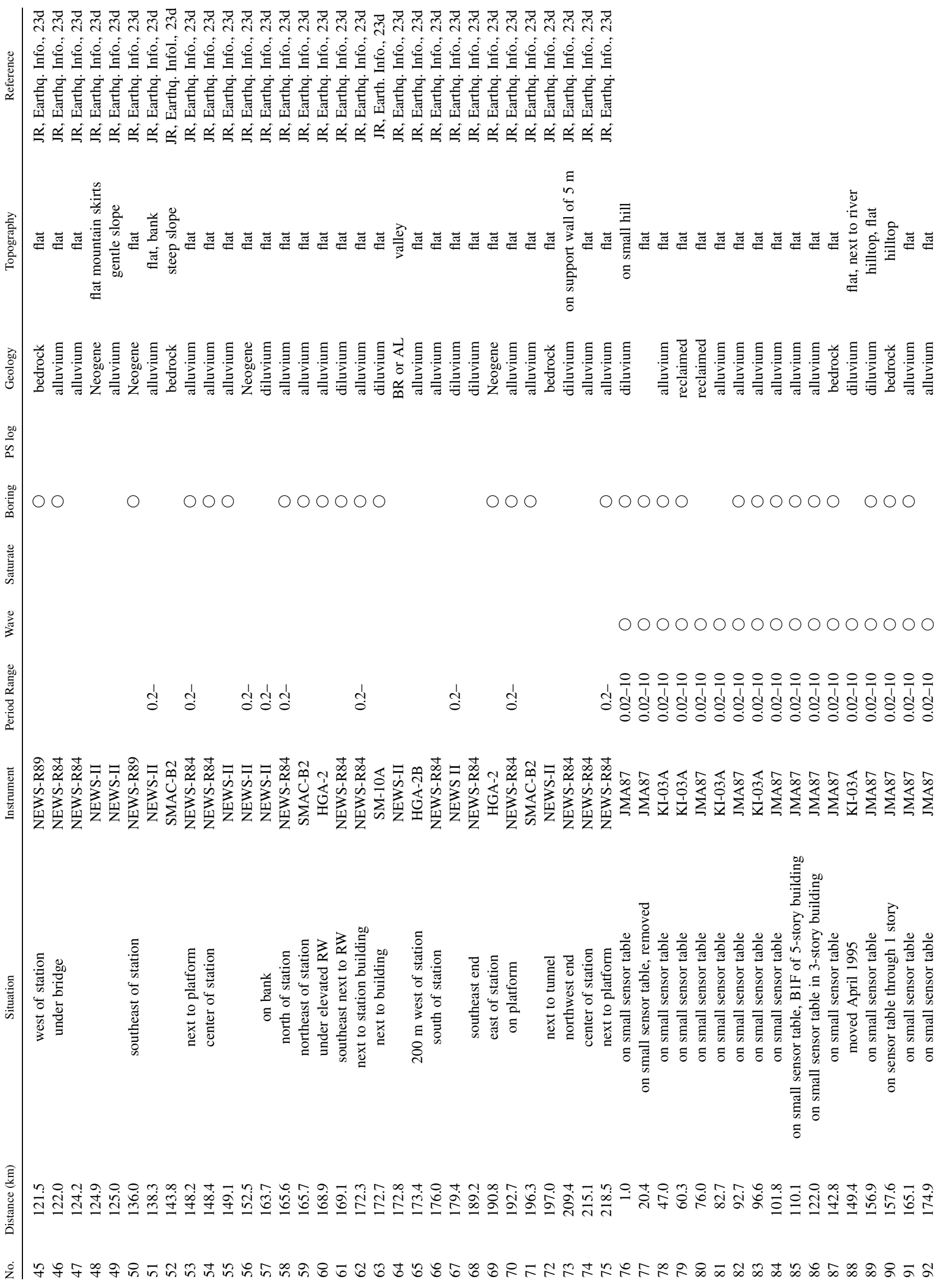




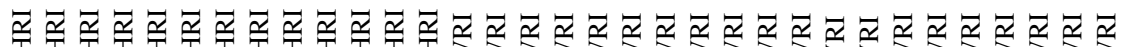

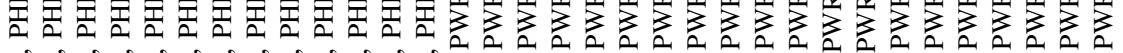

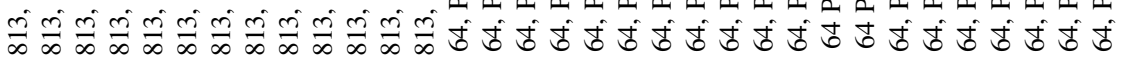

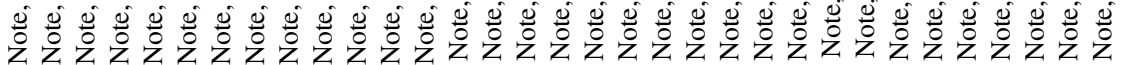

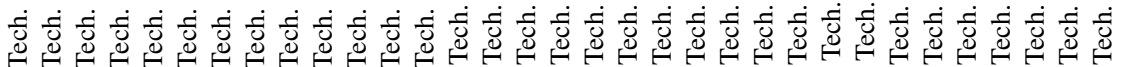

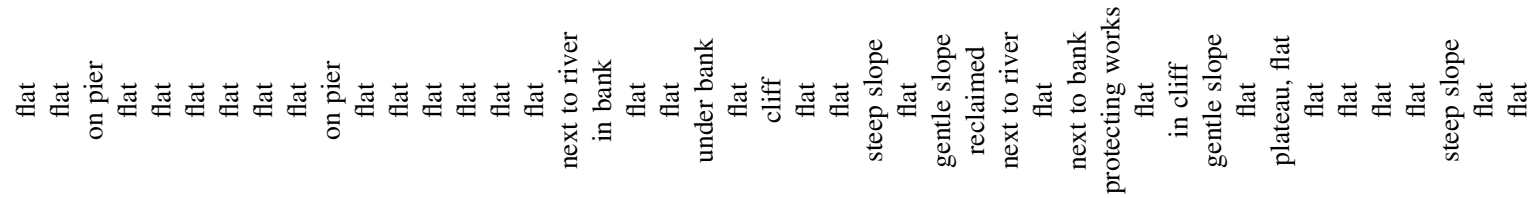

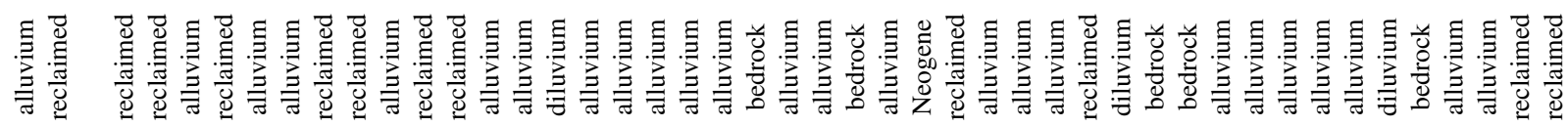
$\bigcirc$

$\bigcirc \bigcirc \bigcirc \bigcirc \bigcirc \bigcirc \bigcirc \bigcirc \bigcirc \bigcirc \bigcirc \bigcirc \bigcirc \bigcirc \bigcirc$

$\bigcirc \bigcirc \bigcirc \bigcirc \bigcirc$

$\bigcirc \bigcirc \bigcirc \bigcirc \bigcirc$

$\bigcirc \bigcirc \bigcirc \bigcirc \bigcirc \bigcirc \quad \bigcirc \bigcirc \quad \bigcirc$

S

$000000000000000000000000000 \quad 00000 \quad 0000000000,0$

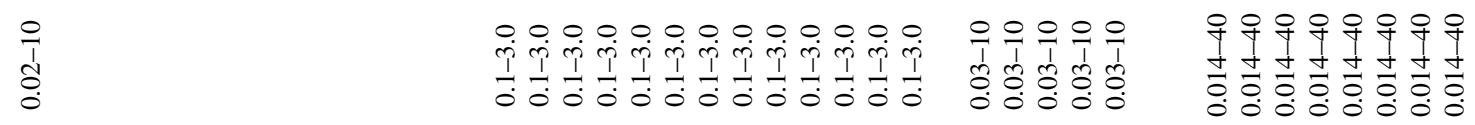

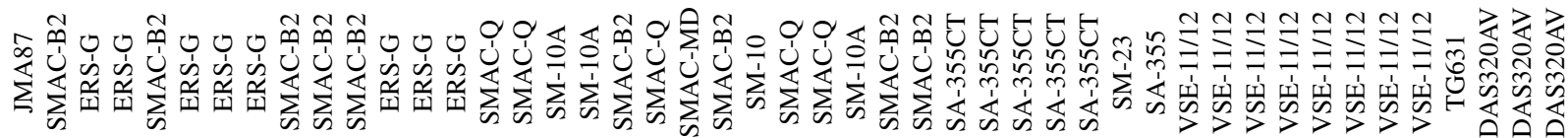

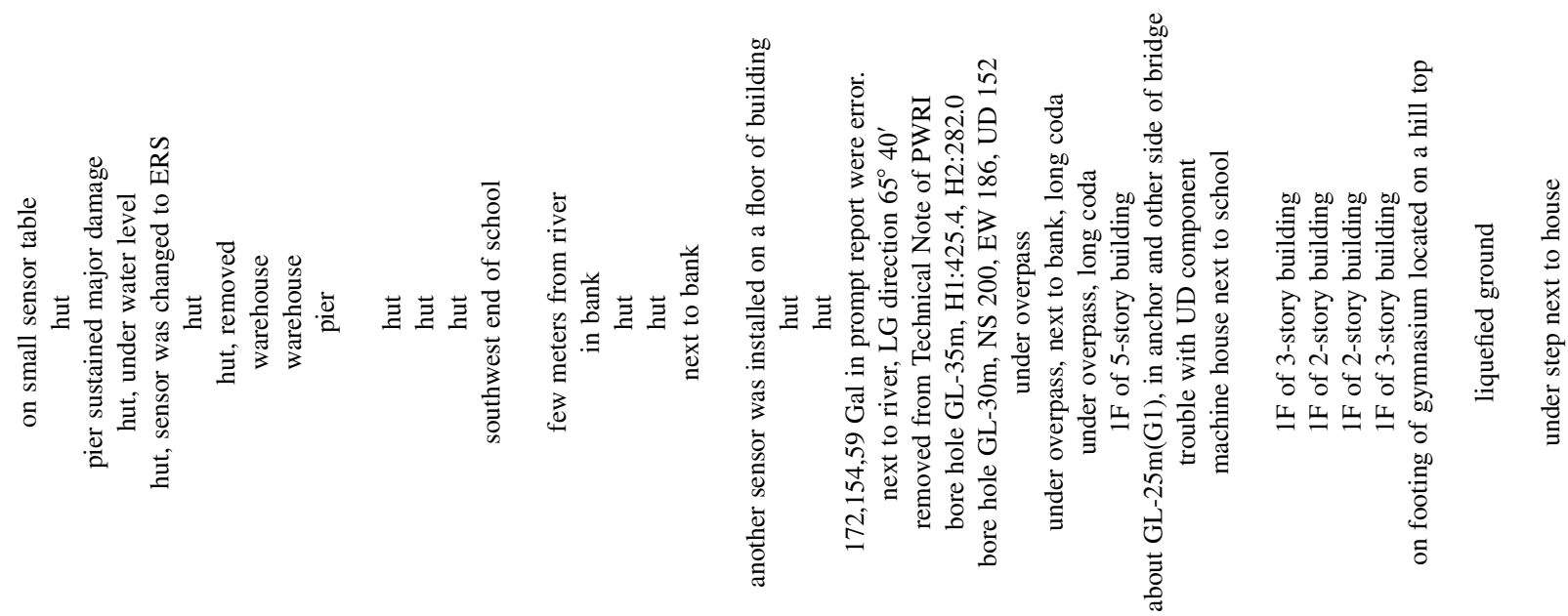

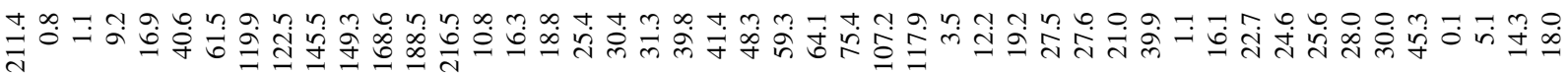

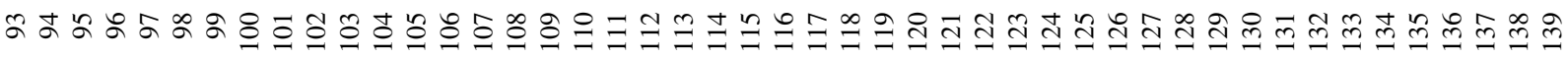




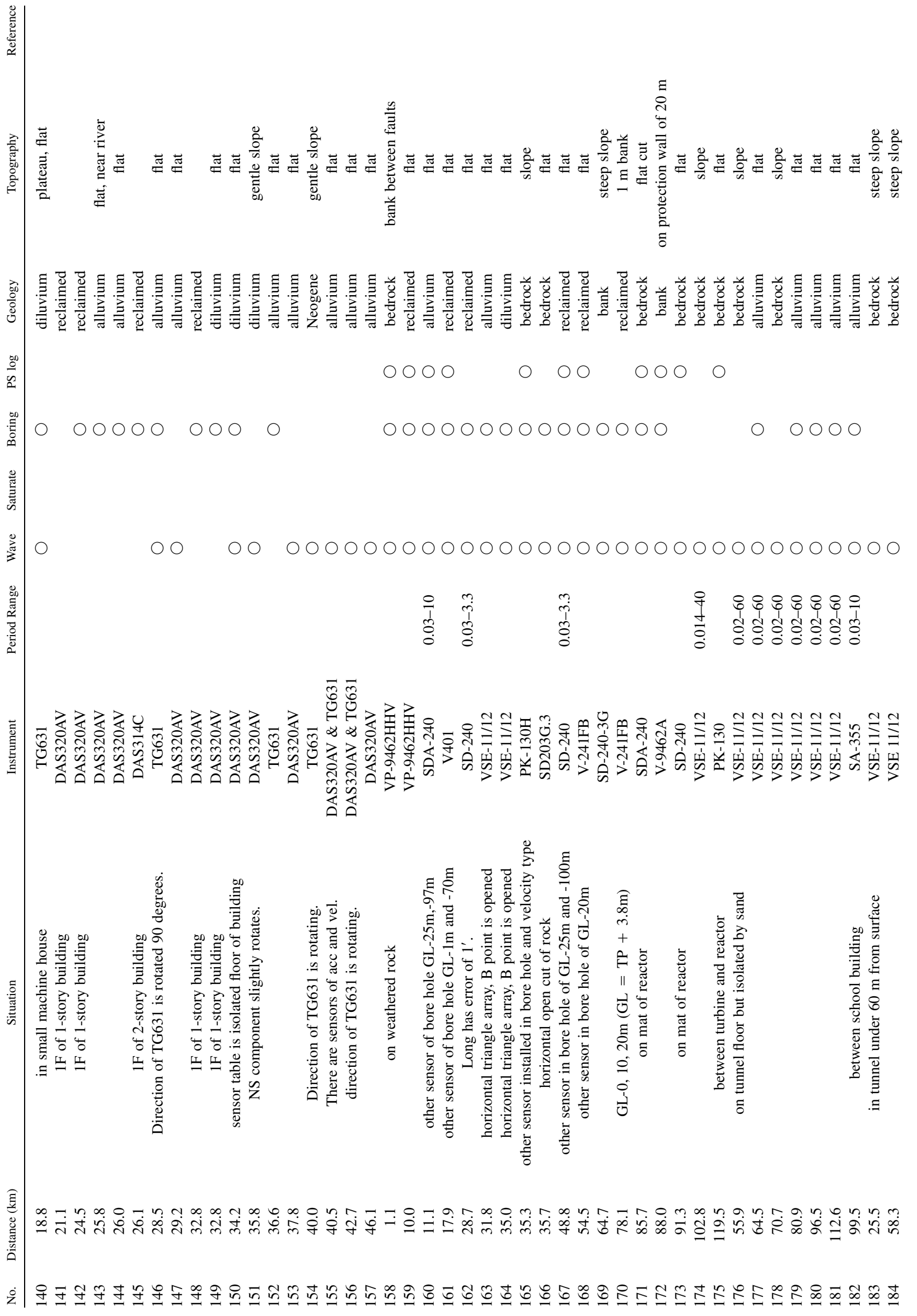




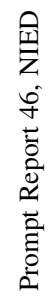

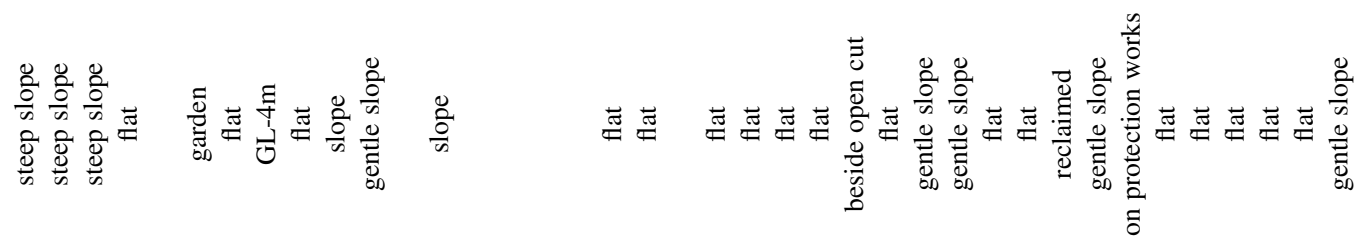

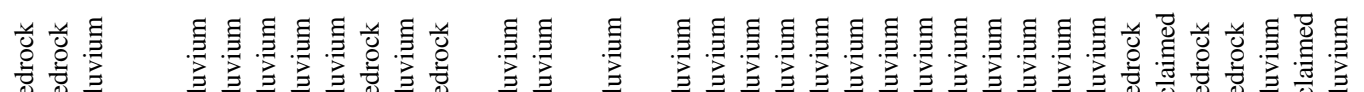

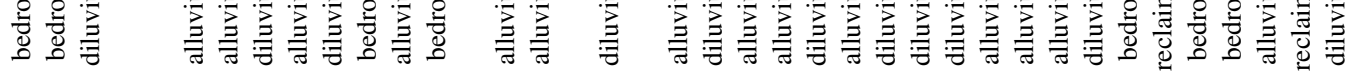

\begin{tabular}{|c|c|c|c|c|c|c|}
\hline & & $\bigcirc \bigcirc$ & $\bigcirc$ & $\bigcirc \bigcirc$ & & 000 \\
\hline$\bigcirc \bigcirc \bigcirc$ & & $\bigcirc \bigcirc \bigcirc$ & $\bigcirc \bigcirc \bigcirc$ & & $\bigcirc \bigcirc \bigcirc \bigcirc \bigcirc \bigcirc ০$ & $\bigcirc \bigcirc \bigcirc \bigcirc$ \\
\hline 奋 & 畜 & & & & 圣盖 & \\
\hline
\end{tabular}

००००००००००000000001

i⿱宀

$\bigcirc \bigcirc \bigcirc \bigcirc \bigcirc$

$\overbrace{0}^{\infty}$

$\begin{array}{lll}0 & 0 \\ 0 & 0 \\ 0 & 0 \\ 0 & 0 \\ 0 & 0 \\ 0\end{array}$

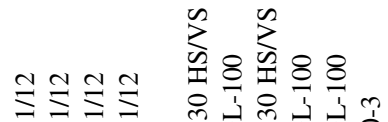

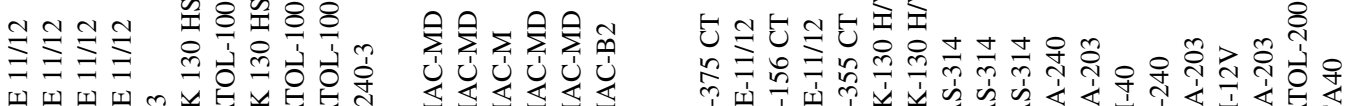

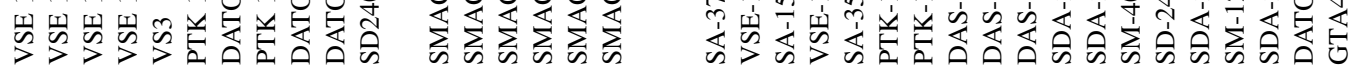
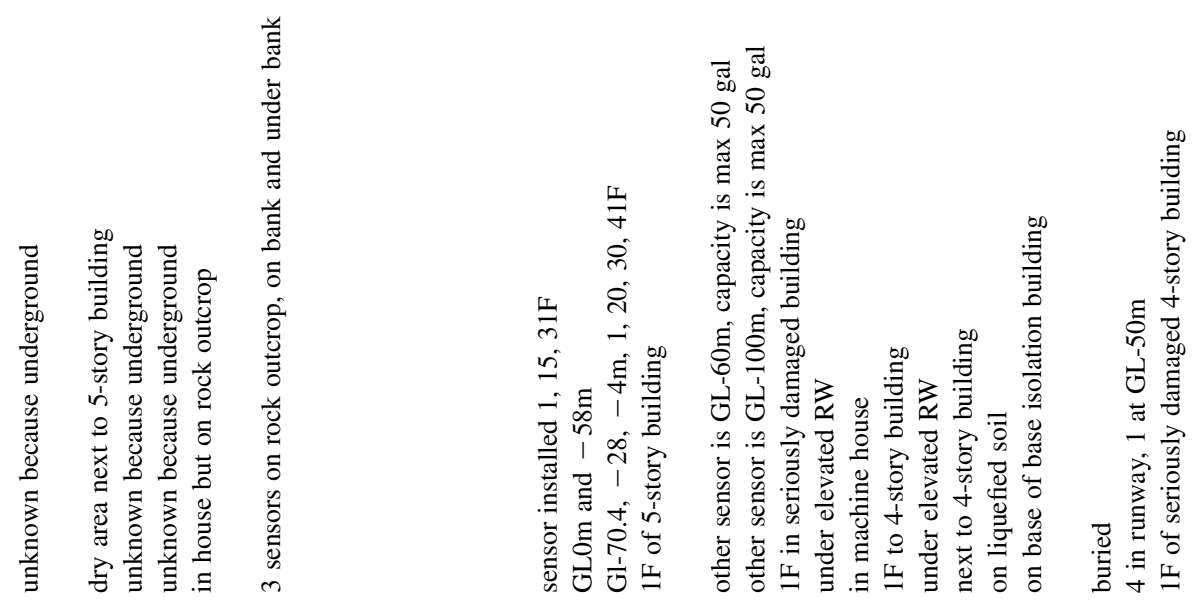

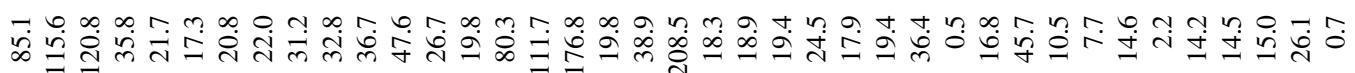

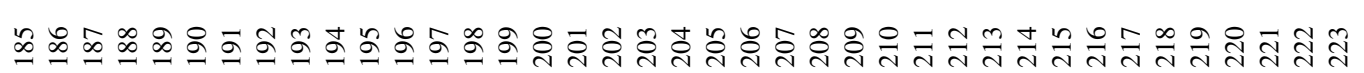

